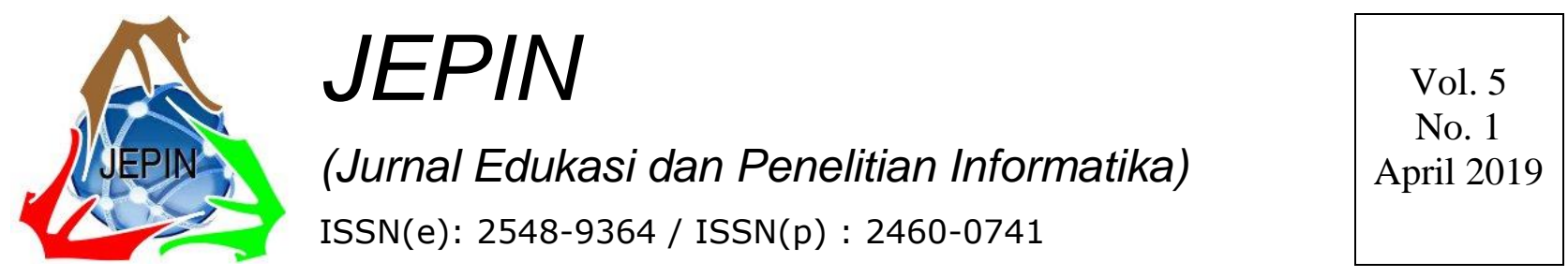

\title{
Analisis Pengaruh Banyak Orde pada Metode Multivariate High-Order Fuzzy Time Series untuk Prediksi Duga Muka Air Waduk
}

\author{
Dwi Kartini $^{\# 1}$, Husna Rusdiani ${ }^{\# 2}$, Andi Farmadi ${ }^{\# 3}$ \\ ${ }^{\#}$ Program Studi Ilmu Komputer Fakultas Matematika dan Ilmu Pengetahuan Alam, Universitas Lambung Mangkurat \\ Jalan Ahmad Yani Km. 36 Banjarbaru \\ ${ }^{1} \mathrm{dwikartini@ulm.ac.id}$ \\ ${ }^{2}$ rusdianihusnalgmail.com \\ ${ }^{3}$ andifarmadi@ulm.ac.id
}

\begin{abstract}
Abstrak- Duga Muka Air (DMA) merupakan salah satu faktor yang sangat penting bagi PLTA dalam melakukan pembangkitan listrik, sehingga DMA harus dikontrol sebaik mungkin agar tidak mengalami degradasi berlebihan. Degradasi dan luapan DMA yang berlebihan perlu dikontrol, sehingga perlu dilakukan prediksi DMA agar dapat mempermudah pihak PLTA dalam melakukan pengontrolan tinggi DMA. Duga Muka Air PLTA dipengaruhi oleh dua faktor, yakni inflow dan outflow air waduk. Pada penelitian ini, dilakukan prediksi Duga Muka Air dengan menggunakan metode Multivariate high-order Fuzzy Time Series . Penelitian ini menggunakan data harian DMA, Inflow, dan Outflow air waduk, dimana DMA menjadi faktor utama dan Inflow dan Outflow menjadi faktor pendukung. Multivariate high-order fuzzy time series merupakan salah satu pengembangan dari metode fuzzy time series yang dapat digunakan untuk melakukan peramalan dengan menggunakan data kurun waktu. Berdasarkan penelitian ini, didapatkan bahwa prediksi DMA dengan menggunakan metode multivariate high-order fuzzy time series memiliki nilai MAPE yang rendah, dimana nilai MAPE terbaik didapat pada saat pengujian dengan menggunakan rentang waktu tiga bulan dengan nilai MAPE untuk orde 1 hingga 5 secara berturut-turut adalah $\mathbf{0 . 0 6 1 6 9 \%}, 0.02535 \%, 0.018 \%, 0.01598 \%$, dan $0.01598 \%$. Pada metode multivariate high order fuzzy time series, didapatkan bahwa faktor pendukung dan banyaknya orde dapat membantu meningkatkan keakuratan prediksi.
\end{abstract}

Kata kunci- Time Series, PLTA, Duga Muka Air, Fuzzy Time Series, Multivariate High-Order Fuzzy Time Series

\section{PENDAhuluan}

Ketersediaan air di dalam kolam tando (reservoir) merupakan salah satu faktor yang memperngaruh terhadap produksi energi listrik yang dapat dihasilkan oleh PLTA
[14]. Ketinggian Duga Muka Air dipengaruhi oleh dua hal, pertama adalah jumlah masuknya air (inflow) dan air yang digunakan untuk memutar turbin (outflow). Diketahui bahwa Duga Muka Air (DMA) sangatlah berpengaruh dalam operasi pembangkitan listrik, sehingga DMA harus dikontrol sebaik mungkin agar tidak mengalami degradasi berlebihan, yang mengakibatkan PLTA tidak dapat melakukan operasi pembangkitan listrik. DMA juga tidak boleh melebih titik maksimum agar tidak terjadi luapan air yang dapat berakibat fatal bagi lingkungan sekitar [13].

Data urut waktu merupakan kumpulan pengamatan data yang terurut dalam suatu kurun waktu. Metode time series merupakan metode prediksi yang menggunakan analisis pola relasi antar variabel yang akan diprediksi dengan variabel waktu. Dalam melakukan prediksi suatu data time series tipe atau pola data sangat perlu untuk diperhatikan [3]. Salah satu pola data time series adalah pola data musiman, yaitu pola data periodik yang terjadi selama kurun waktu satu tahun, yang terdiri atas triwulan, kuartalam, bulanan, mingguan, atau harian [3].

Metode prediksi dengan menggunakan Fuzzy time series pertama kali dikembangkan oleh Song dan Chissom pada tahun 1996 [10]. Song dan Chissom melakukan prediksi untuk mengetahui jumlah pendaftar di Universitas Alabama [10]. Fuzzy time series merupakan salah satu metode soft computing yang telah digunakan dan diterapkan dalam melakukan analisis data runtun waktu. Tujuan utama dari fuzzy time series adalah untuk memprediksi data runtun waktu yang dapat digunakan secara luas pada sembarang data real time [4].

Multivariate-High-Order Fuzzy Time Series merupakan salah satu pengembangan dari metode fuzzy time series . Pada prediksi dengan menggunakan multivariate high-order fuzzy time series, memiliki 
langkah-langkah yang sama dengan langkah-langkah yang digunakan untuk melakukan prediksi dengan menggunakan metode fuzzy time series biasa. .Pada penelitian yang dilakukan oleh I Made Candra Satria pada tahun 2015, dimana ia melakukan komparasi prediksi jumlah wisatawan Australia ke Bali menggunakan metode fuzzy time series dengan multivariate high-order fuzzy time series, hasil prediksi menunjukkan bahwa prediksi dengan menggunakan multivariate high-order fuzzy time series memiliki keakuratan lebih tinggi dibanding dengan menggunkan fuzzy time series tanpa faktor pendukung [10]. Sedangkan pada penelitian yang dilakukan oleh Tahseen Ahmed Jilani di tahun 2008. Jilani menyatakan bahwa metode multivariate high order fuzzy time series dapat menghasilkan prediksi yang lebih akurat [5].

Berdasarkan uraian tersebut maka akan dilakukan penelitian untuk melakukan prediksi Duga Muka Air Waduk PLTA dengan menggunakan metode multivariate high order fuzzy time series. Pada penelitian ini, peramalan akan dilakukan dengan mempertimbangkan tiga buah faktor, yaitu faktor ketinggian DMA, volume air masuk (inflow), dan volume air keluar (outflow) dengan ketinggian DMA sebagai faktor utama dan dua faktor lainnya sebagai faktor pendukung. Peramalan pada penelitian ini juga akan menggunakan perubahan persentase data historis dari DMA, inflow dan outflow, yang mana menurut penelitian sebelumnya dapat meningkatkan keakuratan peramalan.

\section{MULTIVARIATE HIGH-ORDER FUZZY TIME SERIES}

Misalkan $F(t)$ merupakan fuzzy time series . Jika $F(t)$ diakibatkan oleh $F 1(t-1), F 2(t-1)),(F 1(t-2), \quad F 2(t-2))$,.., $F(t-n)$, maka relasi logika fuzzy dapat dituliskan sebagai $(F 1(t-n), F 2(t-n)), \ldots,(F 1(t-2), F 2(t-2)),(F 1(t-1), F 2(t-1))$ $\rightarrow F(t)$. Persamaan tersebut disebut sebagai pemodelan dual faktor orde ke-n peramalan fuzzy time series. Dimana $F 1(t)$ dan $F 2(t)$ disebut sebagai faktor utama dan faktor pendukung. Dengan cara yang sama, maka kita dapat mendefinisikan $m$-faktor orde ke- $n$ relasi logika fuzzy dengan persamaan $(F 1(t-n), F 2(t-n)), \ldots,(F m(t-n)), \ldots$, $(F 1(t-2), \ldots, F m(t-2)),(F 1(t-1), F 2(t-1), \ldots, F m(t-1))) \rightarrow F(t)$. Pada persamaan ini, $F 1(t)$ disebut sebagai faktor utama dan $F 2(t), \quad F 3(t), \ldots, \quad F m(t)$ disebut sebagai faktor pendukung fuzzy time series [8].

Pada multivariate high-order fuzzy time series, tahaptahap yang perlu dilakukan untuk melakukan prediksi, pada dasarnya sama dengan metode fuzzy time series yang telah diajukan oleh Song dan Chissom [10] dan Chen [2]. Berikut ini adalah langkah-langkah untuk melakukan prediksi berdasarkan pada [5] dan [6] dengan menggunakan multivariate high-order fuzzy time series .

1. Definisikan himpunan semesta $U$ dari faktor utama dengan persamaan [10]

$U=\left|D_{\min }-D_{1}, D_{\max }+D_{2}\right| \ldots$ (1)

dimana $D_{\text {min }}$ dan $D_{\max }$ merupakan nilai minimum dan maksimum data historis faktor utama, sedangkan $D_{1}$ dan $D_{2}$ merupakan bilangan real positif sembarang untuk membagi himpunan semesta menjadi beberapa interval $u_{1}, u_{2}, \ldots, u_{i}$ dengan panjang yang sama. Kemudian, dengan cara yang sama definisikan himpunan semesta faktor pendukung.

2. Definisikan nilai linguistik $A_{i}$, yang didefinisikan oleh fuzzy set dari faktor utama dan nilai linguistik dari faktor pendukung yang direpresentasikan dengan $B_{i, j}$, dimana $i=1,2, \ldots, \mathrm{m}-1, j=1,2, \ldots, \mathrm{n}$.

3. Fuzzifikasikan data historis dari faktor utama dan faktor pendukung.

a. Temukan interval $u_{1}, 1=1,2, . ., \mathrm{p}$, yang mana terdapat nilai dari faktor utama pada data historis, dengan beberapa kondisi berikut:

Kondisi 1. Jika nilai dari faktor utama terdapat pada interval $u_{l}$, maka nilai dari faktor utama tersebut difuzzifikasikan ke dalam $1 / A_{1}+0,5 / A_{2}+$ $0,0 / A_{3}$, yang dinotasikan dengan $\mathrm{X}_{1}$.

Kondisi 2. Jika nilai dari faktor utama terdapat pada interval $u_{l}, l=2,3, \ldots, p-1$, maka nilai dari faktor utama tersebut difuzzifikasikan ke dalam $0,5 / A_{\mathrm{i}-1}+1 / A_{\mathrm{i}}+0,5 / A_{\mathrm{i}+1}$, yang dinotasikan dengan $\mathrm{X}_{\mathrm{i}}$.

Kondisi 3. Jika nilai dari faktor utama terdapat pada interval $u_{p}$, maka nilai dari faktor utama tersebut difuzzifikasikan ke dalam $0 / A_{\mathrm{n}-2}+0,5 / A_{\mathrm{n}-1}$ $+1 / A_{\mathrm{n}}$, yang dinotasikan dengan $\mathrm{X}_{\mathrm{n}}$.

b. Untuk faktor pendukung, temukan interval $v_{\mathrm{i}, \mathrm{l}}$, yang mana terdapat nilai dari faktor utama pada data historis, dengan beberapa kondisi berikut:

Kondisi 1. Jika nilai dari faktor pendukung ke- $i$ terdapat pada interval $v_{i, l}$, maka nilai dari faktor pendukung tersebut difuzzifikasikan ke dalam $1 / B_{\mathrm{i}, 1}+0,5 / B_{\mathrm{i}, 2}+0,0 / B_{\mathrm{i}, 3}$, yang dinotasikan dengan $Y_{\mathrm{i}, 1}=\left[Y_{1,1}, Y_{2,1}, \ldots, Y_{\mathrm{m}-1,1}\right]$.

Kondisi 2. Jika nilai dari faktor pendukung ke- $i$ terdapat pada interval $v_{i, l}, l=2,3, \ldots, p-1$, maka nilai dari faktor pendukung ke- $i$ tersebut difuzzifikasikan ke dalam $0,5 / B_{\mathrm{i}, \mathrm{j}-1}+1 / B_{\mathrm{i}, \mathrm{j}}+$ $0,5 / B_{\mathrm{i}, \mathrm{j}+1}$, dimana $j=i=2,3, \ldots, \mathrm{n}-1$ yang dinotasikan dengan $Y_{\mathrm{i}, \mathrm{j}}, j=2,3, . ., \mathrm{n}-1$.

Kondisi 3. Jika nilai dari faktor pendukung ke- $i$ terdapat pada interval $v_{\mathrm{i} p}$, maka nilai dari faktor pendukung tersebut difuzzifikasikan ke dalam $0 / B_{\mathrm{i}, \mathrm{n}-2}+0,5 / B_{\mathrm{i}, \mathrm{n}-1}+1 / B_{\mathrm{n}}$, yang dinotasikan dengan $Y_{\mathrm{i}, \mathrm{n}}$.

4. Bentuk relasi logika fuzzy dari faktor ke-m orde ke- $k$ berdasarkan nilai fuzzifikasi data historis dari faktor utama dan faktor pendukung. Persamaan bentuk relasi dapat dituliskan dengan $\left(X_{\mathrm{j}-\mathrm{k}} ; Y_{2, \mathrm{j}-\mathrm{k}}, \ldots, Y_{\mathrm{m}-1, \mathrm{j}-\mathrm{k}}\right), \ldots,\left(X_{\mathrm{j}-2}\right.$; $\left.Y_{2, \mathrm{j}-2}, \ldots, Y_{\mathrm{m}-1, \mathrm{j}-2}\right),\left(X_{\mathrm{j}-1}, Y_{1, \mathrm{j}-1}, Y_{2, \mathrm{j}-1}, \ldots, Y_{\mathrm{m}-1, \mathrm{j}-1}\right) \rightarrow X_{\mathrm{j}}$, dimana $\mathrm{j}>\mathrm{k}$, dan $X_{\mathrm{j}-\mathrm{k}}$ menampilkan step ke- $k$ ketergantungan dari nilai ke-j faktor utama $X_{\mathrm{j}}, Y_{\mathrm{i}}, \mathrm{j}-\mathrm{k}, \mathrm{i}=1,2, \ldots, \mathrm{m}-1, \mathrm{j}$ $=1,2, \ldots, \mathrm{k}$. Kemudian bagi relasi logikal fuzzy (FLR) ke dalam kelompok relasi logikal fuzzy (FLRG) berdasarkan status saat ini dari relasi logikal fuzzy. Faktor pendukung berperan seperti komponen pendukung terhadap m-dimensional vektor kondisi.

5. Hitung nilai prediksi berdasarkan prinsip-prinsip yang dijabarkan pada [7] : 
(1) Jika m-faktors orde ke-k nilai fuzzifikasi data historis sebelum hari ke-i adalah $\left(X_{\mathrm{ik}}, Y_{\mathrm{ik}}\right),\left(X_{\mathrm{i}(\mathrm{k}-1)}\right.$, $Y_{\mathrm{i}(\mathrm{k}-1)}, \ldots$, dan $\left(X_{\mathrm{i} 1}, Y_{\mathrm{i} 1}\right)$ dimana $\mathrm{k} \geq 2 ; \mathrm{k}$ adalah banyak nya orde; $X$ dan $Y$ melambangkan nilai fuzzyfikasi faktor utama dan pendukung berturutturut; $X_{\mathrm{ik}}, X_{\mathrm{i}(\mathrm{k}-1)}, . ., X_{\mathrm{i} 1}$ dan $X_{\mathrm{j}}$ merupakan nilai fuzzifikasi yang direpresentasikan oleh fuzzy set dari faktor utama; $Y_{\mathrm{ik}}, Y_{\mathrm{i}(\mathrm{k}-1)}, \ldots, Y_{\mathrm{i} 1}$ merupakan nilai fuzzyfikasi yang direpresentasikan oleh fuzzy set faktor pendukung, dan pada FLR di orde ke- $k$ FLRG adalah $\left(X_{\mathrm{ik}}, Y_{\mathrm{ik}}\right),\left(X_{\mathrm{i}(\mathrm{k}-1)}, Y_{\mathrm{i}(\mathrm{k}-1)}\right), \ldots,\left(X_{\mathrm{i} 1}, Y_{\mathrm{i} 1}\right)$ $\rightarrow X_{\mathrm{j}}$, maka nilai prediksi $\mathrm{t}_{\mathrm{j}}$ dari hari ke-i dihitung dengan menggunakan persamaan berikut:

$$
t_{j}=\left\{\begin{array}{cc}
\frac{m_{1}+0,5 m_{2}}{1+0,5}, & j i k a j=1 \\
\frac{0,5 m_{j-1}+m_{j}+0,5 m_{j+1}}{0,5+1+0,5} & , j i k a 2 \leq j \leq n-1 \\
\frac{0,5 m_{n-1}+m_{n}}{0,5+1} & , j i k a j=n
\end{array} .\right.
$$

Dimana $m_{\mathrm{j}-1}, m_{\mathrm{j}}, m_{\mathrm{j}+1}$ adalah nilai tengah dari interval $u_{\mathrm{j}-1}, u_{\mathrm{j}}$, dan $u_{\mathrm{j}+1}$. Sedangkan nilai $j$ adalah indeks yang menunjukkan nilai fuzzy set yang banyaknya dilambangkan dengan $n$. Jika m-faktor orde ke-k nilai fuzzifikasi data historis sebelum hari ke-i adalah $\left(X_{\mathrm{ik}}, Y_{\mathrm{ik}}\right),\left(X_{\mathrm{i}(\mathrm{k}-1)}, Y_{\mathrm{i}(\mathrm{k}-1)}, \ldots\right.$, dan $\left(X_{\mathrm{i} 1}, Y_{\mathrm{i} 1}\right)$ dimana $\mathrm{k} \geq 2$; k adalah banyaknya orde; $X$ dan $Y$ melambangkan nilai fuzzyfikasi faktor utama dan pendukung berturut turut $X_{\mathrm{ik}}, X_{\mathrm{i}(\mathrm{k}-1)}, \ldots, X_{\mathrm{i} 1}$ dan $X_{\mathrm{j}}$ merupakan nilai fuzzifikasi yang direpresentasikan oleh fuzzy set dari faktor utama; $Y_{\mathrm{ik}}, Y_{\mathrm{i}(\mathrm{k}-1)}, \ldots, Y_{\mathrm{i} 1}$ merupakan nilai fuzzyfikasi yang direpresentasikan oleh fuzzy set faktor pendukung, dan pada FLR di orde ke-k FLRG adalah sebagai berikut:

$$
\begin{aligned}
& \left(X_{\mathrm{ik}}, Y_{\mathrm{ik}}\right),\left(X_{\mathrm{i}(\mathrm{k}-1)}, Y_{\mathrm{i}(\mathrm{k}-1)}\right), \ldots,\left(X_{\mathrm{i} 1}, Y_{\mathrm{i} 1}\right) \rightarrow X_{\mathrm{j} 1} \\
& \left(X_{\mathrm{ik}}, Y_{\mathrm{ik}}\right),\left(X_{\mathrm{i}(\mathrm{k}-1)}, Y_{\mathrm{i}(\mathrm{k}-1)}\right), \ldots,\left(X_{\mathrm{i} 1}, Y_{\mathrm{i} 1}\right) \rightarrow X_{\mathrm{j} 2} \\
& \ldots \\
& \left(X_{\mathrm{ik}}, Y_{\mathrm{ik}}\right),\left(X_{\mathrm{i}(\mathrm{k}-1)}, Y_{\mathrm{i}(\mathrm{k}-1)}\right), \ldots,\left(X_{\mathrm{i} 1}, Y_{\mathrm{i} 1}\right) \rightarrow X_{\mathrm{jp}}
\end{aligned}
$$

Dimana $\mathrm{k}$ adalah banyaknya orde, $i$ merupakan indeks yang mewakili banyaknya fuzzy set, $X_{\mathrm{ik}}, X_{\mathrm{i}(\mathrm{k}-}$ 1)..., $X_{\mathrm{j} 1}, X_{\mathrm{j} 2}, \ldots$, dan $X_{\mathrm{jp}}$ adalah fuzzy sets dari faktor utama dan $Y_{\mathrm{ik}}, Y_{(\mathrm{k}-1)}, \ldots, Y_{\mathrm{i} 1}$ adalah fuzzy set dari faktor pendukung dan bilangan dari $X_{\mathrm{j} 1}, X_{\mathrm{j} 2}, .$. , dan $X_{\text {jp }}$, dimana indeks $p$ menunjukkan banyaknya FLRG yang muncul, sedangkan indeks $j$ mewakili nilai fuzzy set dari $\mathrm{X}$ yang muncul. $X_{\mathrm{j} 1}, X_{\mathrm{j} 2}, .$. , dan $X_{\mathrm{jp}}$ yang muncul pada FLRG dilambangkan dengan $n_{\mathrm{j} 1}, n_{\mathrm{j} 2}, \ldots$, dan $n j p$, maka hasil prediksi dapat dihitung dengan menggunakan persamaan berikut:

$$
\frac{n_{j 1} x t_{j 1}+n_{j 2} x t_{j 2}+\cdots+n_{j p} x t_{j p}}{n_{j 1}+n_{i 2}+\cdots+n_{k p}}
$$

Dimana nilai dari $t_{j l}, t_{j 2}, \ldots$, dan $t_{j p}$ dihitung dengan menggunakan persamaan pada prinsip pertama.

(2) Jika m-faktor orde ke-k nilai fuzzyfikasi data historis sebelum hari ke-i adalah $\left(X_{\mathrm{ik}}, Y_{\mathrm{ik}}\right),\left(X_{\mathrm{i}(\mathrm{k}-1)}\right.$, $Y_{\mathrm{i}(\mathrm{k}-1)}, \ldots$, dan $\left(X_{\mathrm{i} 1}, Y_{\mathrm{i} 1}\right)$, dimana $k \geq 2 ; \mathrm{k}$ adalah banyak nya orde; $X$ dan $Y$ melambangkan nilai fuzzyfikasi faktor utama dan pendukung berturut turut; $X_{\mathrm{ik}}, X_{\mathrm{i}(\mathrm{k}-1)}, . ., X_{\mathrm{i} 1}$ dan $X_{\mathrm{j}}$ merupakan nilai fuzzifikasi yang direpresentasikan oleh fuzzy set dari faktor utama; $Y_{\mathrm{ik}}, Y_{\mathrm{i}(\mathrm{k}-1)}, \ldots, Y_{\mathrm{i} 1}$ merupakan nilai fuzzyfikasi yang direpresentasikan oleh fuzzy set faktor pendukung, dan pada FLR di orde ke-k FLRG adalah tidak diketahui atau digambarkan dengan \#, dengan persamaannya adalah $\left(X_{\mathrm{ik}}, Y_{\mathrm{ik}}\right)$, $\left(X_{\mathrm{i}(\mathrm{k}-1)}, \quad Y_{\mathrm{i}(\mathrm{k}-1)}\right), \quad \ldots, \quad\left(X_{\mathrm{i} 1}, Y_{\mathrm{i} 1}\right) \rightarrow \#$, maka untuk menghitung hasil prediksi dilakukan dengan persamaan:

$$
\frac{1 x t_{i k}+2 x t_{i(k-1)}+\cdots+k x t_{i 1}}{1+2+\cdots+k}
$$

Dimana nilai dari $t_{i k}, t_{i(k-1)}, \ldots$ dan $t_{i 1}$ dihitung dengan menggunakan persamaan pada prinsip pertama atau persamaan 8 .

\section{PEMBAHASAN}

Berikut ini adalah proses prediksi Duga Muka Air Waduk dengan menggunakan metode multivariate highorder fuzzy time series. Data yang digunakan merupakan data kurun waktu pencatatan DMA, inflow, dan outflow waduk selama 1 tahun yang diolah dengan menggunakan Microsoft Excel.

\section{A. Mengubah Data Menjadi Persentase}

Variabel yang digunakan pada penelitian ini adalah data tinggi Duga Muka Air (DMA) waduk, variabel inflow air waduk, serta variabel outflow air waduk. Variabel tersebut merupakan data kurun waktu harian dari tanggal 1 Desember 2016 hingga 31 Desember 2017. Variabel tersebut dibagi menjadi dua kategori, yakni variabel faktor utama dan variabel faktor pendukung. Variabel yang akan diprediksi adalah tinggi Duga Muka Air waduk, yang mana pada teori metode Multivariate High Order Fuzzy Time Series sehingga variabel yang menjadi faktor utama adalah variabel yang akan diprediksi nilainya. Sementara itu, faktor pendukung pada penelitian ini adalah variabel Inflow air dan Outflow air waduk. Kedua variabel tersebut dijadikan sebagai faktor pendukung dikarenakan kedua variabel tersebut merupakan faktor yang mempengaruhi fluktuasi tinggi Duga Muka Air waduk.

Pada penelitian ini, prediksi tinggi Duga Muka Air waduk akan dilakukan dengan menggunakan data persentase perubahan kenaikan data. Sehingga, data kurun waktu DMA, Inflow air, dan Outflow air akan dirubah menjadi data persentase terlebih dahulu [8] dan [9]. Pengkonversian data aktual menjadi data persentase tersebut dilakukan dengan menggunakan persamaan

$$
\frac{t_{j}-t_{j-1}}{t_{j-1}} \times 100 \%
$$

dimana $t_{j}$ adalah data sekarang dan $t_{j-1}$ adalah data sebelumnya. Data perubahan persentase tersebut selanjutnya akan kembali dirubah menjadi data aktual setelah didapat nilai hasil prediksi dari DMA. Berdasarkan perhitungan dengan persamaan tersebut, didapatkan hasil 
perubahan persentase untuk DMA, Inflow, dan Outflow adalah sebagai berikut:

TABEL I

DATA AKTUAL DAN DATA PERSENTASE DMA DARI 1 SEPTEMBER - 31 DESEMBER 2017

\begin{tabular}{|l|l|l|}
\hline Tanggal & Data Aktual & Data Persentase (\%) \\
\hline $01-09-2017$ & 58.830 & -0.1104 \\
\hline $02-09-2017$ & 58.760 & -0.1190 \\
\hline $03-09-2017$ & 58.740 & -0.0340 \\
\hline$\ldots$ & $\ldots$ & $\ldots$ \\
\hline $29-12-2017$ & 56,620 & $-0,0177$ \\
\hline $30-12-2017$ & 56,600 & $-0,0353$ \\
\hline $31-12-2017$ & 56,560 & $-0,0707$ \\
\hline
\end{tabular}

TABEL II

DATA AKTUAL DAN DATA PERSENTASE INFLOW DAN OUTFLOW DARI 1 SEPTEMBER - 31 DESEMBER 2017

\begin{tabular}{|c|c|c|c|c|}
\hline Tanggal & \multicolumn{2}{|c|}{ Inflow } & \multicolumn{2}{c|}{ Outflow } \\
\hline & Data Aktual & $\begin{array}{l}\text { Data } \\
\text { Persent } \\
\text { ase (\%) }\end{array}$ & Data Aktual & $\begin{array}{l}\text { Data } \\
\text { Persentas } \\
\text { e } \%)\end{array}$ \\
\hline $01-09-2017$ & 1077176.750 & -34.51 & 4709851.00 & 54.82 \\
\hline $02-09-2017$ & 394807.6875 & -63.34 & 4306918.00 & -8.55 \\
\hline$\ldots$ & $\ldots$ & $\ldots$ & $\ldots$ & $\ldots$ \\
\hline$\ldots$ & $\ldots$ & $\ldots$ & $\ldots$ & $\ldots$ \\
\hline $29-12-2017$ & $4.185 .404,12$ & 18,73 & $4.744 .277,00$ & 16,11 \\
\hline $30-12-2017$ & $3.057 .043,39$ & $-26,95$ & $4.174 .789,00$ & $-12,00$ \\
\hline $31-12-2017$ & $2.091 .548,85$ & $-31,58$ & $4.327 .041,00$ & 3,64 \\
\hline
\end{tabular}

B. Prediksi dengan Metode Multivariate high-order Fuzzy time series

Berdasarkan langkah-langkah yang ada pada metode Multivariate high-order Fuzzy time series, maka prediksi Duga Muka Air Waduk PLTA adalah sebagai berikut:

1. Pendefinisian Himpunan Semesta

Himpunan semesta pada metode fuzzy time series digunakan untuk menentukan besar interval dan pembagian range data interval untuk prediksi DMA. Pendefinisian himpunan semesta dilakukan dengan menggunakan persamaan $\left|\mathrm{Dmin}-\mathrm{D}_{1}, \mathrm{Dmax}+\mathrm{D}_{2}\right|$, yang mana $\mathrm{D}_{\min }$ dan $\mathrm{D}_{\max }$ merupakan nilai minimum dan maksimum dari sebuah range data. Sedangkan nilai $D_{1}$ dan $D_{2}$ merupakan dua bilangan riil positif yang dipilih secara sembarang. Dengan menggunakan pengujian untuk melakukan prediksi tanggal 1 Desember 2017, dengan menggunakan rentang data historis selama 3 bulan, berikut ini merupakan perhitungan himpunan semesta untuk DMA, Inflow, dan Outflow:

$$
\begin{aligned}
& \text { a. } U \text { DMA }=\left[U_{1 D M A}, U_{2 \mathrm{DMA}}\right] \text {; } \\
& =\left[\left|\mathrm{D}_{\text {minDMA }}-\mathrm{D}_{1 \mathrm{DMA}}, \mathrm{D}_{\text {maxDMA }}+\mathrm{D}_{2 \mathrm{DMA}}\right|\right] \\
& =[-0.1233-0.0767,0.3651+0.0349] \\
& U \text { DMA }=[-0.2,0.4] \text {; } \\
& \text { b. } U \text { Inflow }=\left[U_{\text {IInflow }}, U_{2 \text { Inflow }}\right] \text {; } \\
& =\left[\mid \mathrm{D}_{\text {minInflow }}-\mathrm{D}_{1 \text { Inflow }}, \mathrm{D}_{\text {maxInf;ow }}+\right. \\
& \left.\mathrm{D}_{\text {2Inflow }}\right] \\
& =[-9070.3436-929.6354,1369.7581+ \\
& \text { 630.2419] } \\
& U \text { Inflow }=[-10000,2000] \text {; }
\end{aligned}
$$

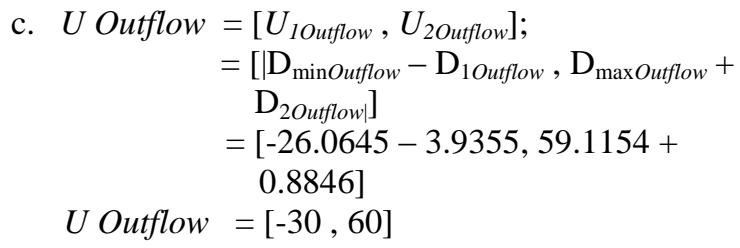

2. Pembentukan Interval Data

Untuk menentukan jumlah interval, dilakukan dengan menggunakan persamaan statistika seperti yang dijabarkan pada [11] sebagai berikut:

$$
\boldsymbol{k}=\mathbf{1}+\mathbf{3 . 3} \log \boldsymbol{n} \ldots(6)
$$

Sedangkan untuk menentukan panjang interval atau jarak antara satu interval ke interval lain dilakukan dengan menggunakan persamaan seperti terdapat pada [11]:

$$
c=\frac{x_{n}-x_{2}}{k}
$$

yang mana $\mathrm{x}_{\mathrm{n}}$ merupakan nilai $\mathrm{U}_{2}$ dan $\mathrm{x}_{1}$ merupakan nilai $\mathrm{U}_{1}$.

Interval untuk DMA, inflow, dan outflow ditunjukkan pada Tabel 3, 4, dan 5:

TABEL III INTERVAL DMA

\begin{tabular}{|c|c|c|}
\hline Interval DMA (ui) & Range & $\begin{array}{c}\text { Nilai } \\
\text { Tengah }\end{array}$ \\
\hline$u_{1}$ & {$[-0.2,-0.125]$} & -0.1625 \\
\hline$u_{2}$ & {$[-0.125,-0.05]$} & -0.0875 \\
\hline$u_{3}$ & {$[-0.05,0.025]$} & -0.0125 \\
\hline$u_{4}$ & {$[0.025,0.1]$} & 0.0625 \\
\hline$u_{5}$ & {$[0.1,0.175]$} & 0.1375 \\
\hline$u_{6}$ & {$[0.175,0.25]$} & 0.2125 \\
\hline$u_{7}$ & {$[0.25,0.325]$} & 0.2875 \\
\hline$u_{8}$ & {$[0.325,0.4]$} & 0.3625 \\
\hline
\end{tabular}

TABEL IV

INTERVAL INFLOW

\begin{tabular}{|c|c|c|}
\hline Interval Inflow $\left(\mathrm{v}_{\mathrm{i}}\right)$ & Rentang & $\begin{array}{c}\text { Nilai } \\
\text { Tengah }\end{array}$ \\
\hline $\mathrm{v}_{1}$ & {$[-10000,-8500]$} & -9250 \\
\hline $\mathrm{v}_{2}$ & {$[-8500,-7000]$} & -7750 \\
\hline$\ldots$ & $\ldots$ & $\ldots$ \\
\hline$\ldots$ & $\ldots$ & $\ldots$ \\
\hline $\mathrm{v}_{6}$ & {$[-2500,-1000]$} & -1750 \\
\hline $\mathrm{v}_{7}$ & {$[-1000,500]$} & -250 \\
\hline $\mathrm{v}_{8}$ & {$[500,1500]$} & 1250 \\
\hline
\end{tabular}

TABEL V

INTERVAL OUTFLOW

\begin{tabular}{|c|c|c|}
\hline Interval Outflow $\left(w_{i}\right)$ & Rentang & $\begin{array}{c}\text { Nilai } \\
\text { Tengah }\end{array}$ \\
\hline $\mathrm{w}_{1}$ & {$[-30,-18.75]$} & -24.375 \\
\hline $\mathrm{w}_{2}$ & {$[-18.75,-7.5]$} & -13.125 \\
\hline$\ldots$ & $\ldots$ & $\ldots$ \\
\hline$\ldots$ & $\ldots$ & $\ldots$ \\
\hline $\mathrm{w}_{6}$ & {$[26.25,37.5]$} & 31.875 \\
\hline $\mathrm{w}_{7}$ & {$[37.5,48.75]$} & 43.125 \\
\hline $\mathrm{w}_{8}$ & {$[48.75,60]$} & 54.375 \\
\hline
\end{tabular}


3. Pendefinisian Fuzzy set

Berdasarkan persamaan pada [1]

$$
\begin{aligned}
& A_{1}=1 / u_{1}+0.5 / u_{2}+0 / u_{3}+0 / u_{4} \ldots+0 / u_{n}, \\
& A_{2}=0.5 / u_{1}+1 / u_{2}+0.5 / u_{3}+0 / u_{4} \ldots+0 / u_{n} \\
& A_{3}=0 / u_{1}+0.5 / u_{2}+1 / u_{3}+0.5 / u_{4} \ldots+0 / u_{n} \\
& \ldots \\
& A_{n}=0 / u_{1}+0 / u_{2}+\ldots+0.5 / u_{n-2}+1 / u_{n-1}+0.5 / u_{n}
\end{aligned}
$$

maka didapatkan fuzzy set untuk prediksi tanggal 1 Desember 2017 dengan data historis sebanyak 3 bulan, yakni dari 1 September 2017 hingga 1 Desember 2017 untuk masing-masing faktor adalah sebagai berikut:

$\mathrm{A}_{1}=1 / u_{1}+0.5 / u_{2}+0 / u_{3}+0 / u_{4}+0 / u_{5}+0 / u_{6}+0 / u_{7}+0 / u_{8}$ $\mathrm{A}_{2}=0.5 / u_{1}+1 / u_{2}+0.5 / u_{3}+0 / u_{4}+0 / u_{5}+0 / u_{6}+0 / u_{7}+0 / u_{8}$ $\mathrm{A}_{3}=0 / u_{1}+0.5 / u_{2}+1 / u_{3}+0.5 / u_{4}+0 / u_{5}+0 / u_{6}+0 / u_{7}+0 / u_{8}$ $\mathrm{A}_{4}=0 / u_{1}+0 / u_{2}+0.5 / u_{3}+1 / u_{4}+0.5 / u_{5}+0 / u_{6}+0 / u_{7}+0 / u_{8}$ $\mathrm{A}_{5}=0 / u_{1}+0 / u_{2}+0 / u_{3}+0.5 / u_{4}+1 / u_{5}+0.5 / u_{6}+0 / u_{7}+0 / u_{8}$ $\mathrm{A}_{6}=0 / u_{1}+0 / u_{2}+0 / u_{3}+0 / u_{4}+0.5 / u_{5}+1 / u_{6}+0.5 / u_{7}+0 / u_{8}$ $\mathrm{A}_{7}=0 / u_{1}+0 / u_{2}+0 / u_{3}+0 / u_{4}+0 / u_{5}+0.5 / u_{6}+1 / u_{7}+0.5 / u_{8}$ $\mathrm{A}_{8}=0 / u_{1}+0 / u_{2}+0 / u_{3}+0 / u_{4}+0 / u_{5}+0 / u_{6}+0.5 / u_{7}+1 / u_{8}$

$\mathrm{B}_{1.1}=1 / v_{1}+0.5 / v_{2}+0 / v_{3}+0 / v_{4}+0 / v_{5}+0 / v_{6}+0 / v_{7}+0 / v_{8}$ $\mathrm{B}_{1.2}=0.5 / v_{1}+1 / v_{2}+0.5 / v_{3}+0 / v_{4}+0 / v_{5}+0 / v_{6}+0 / v_{7}+0 / v_{8}$ $\mathrm{B}_{1.3}=0 / v_{1}+0.5 / v_{2}+1 / v_{3}+0.5 / v_{4}+0 / v_{5}+0 / v_{6}+0 / v_{7}+0 / v_{8}$ $\mathrm{B}_{1.4}=0 / v_{1}+0 / v_{2}+0.5 / v_{3}+1 / v_{4}+0.5 / v_{5}+0 / v_{6}+0 / v_{7}+0 / v_{8}$ $\mathrm{B}_{1.5}=0 / v_{1}+0 / v_{2}+0 / v_{3}+0.5 / v_{4}+1 / v_{5}+0.5 / v_{6}+0 / v_{7}+0 / v_{8}$ $\mathrm{B}_{1.6}=0 / v_{1}+0 / v_{2}+0 / v_{3}+0 / v_{4}+0.5 / v_{5}+1 / v_{6}+0.5 / v_{7}+0 / v_{8}$ $\mathrm{B}_{1.7}=0 / v_{1}+0 / v_{2}+0 / v_{3}+0 / v_{4}+0 / v_{5}+0.5 / v_{6}+1 / v_{7}+0.5 / v_{8}$ $\mathrm{B}_{1.8}=0 / v_{1}+0 / v_{2}+0 / v_{3}+0 / v_{4}+0 / v_{5}+0 / v_{6}+0.5 / v_{7}+1 / v_{8}$

$\mathrm{B}_{2.1}=1 / w_{1}+0.5 / w_{2}+0 / w_{3}+0 / w_{4}+0 / w_{5}+0 / w_{6}+0 / w_{7}+0 / w_{8}$ $\mathrm{B}_{2.2}=0.5 / w_{1}+1 / w_{2}+0.5 / w_{3}+0 / w_{4}+0 / w_{5}+0 / w_{6}+0 / w_{7}+0 / w_{8}$ $\mathrm{B}_{23}=0 / w_{1}+0.5 / w_{2}+1 / w_{3}+0.5 / w_{4}+0 / w_{5}+0 / w_{6}+0 / w_{7}+0 / w_{8}$ $\mathrm{B}_{2.4}=0 / w_{1}+0 / w_{2}+0.5 / w_{3}+1 / w_{4}+0.5 / w_{5}+0 / w_{6}+0 / w_{7}+0 / w_{8}$ $\mathrm{B}_{2.5}=0 / w_{1}+0 / w_{2}+0 / w_{3}+0.5 / w_{4}+1 / w_{5}+0.5 / w_{6}+0 / w_{7}+0 / w_{8}$ $\mathrm{B}_{2.6}=0 / w_{1}+0 / w_{2}+0 / w_{3}+0 / w_{4}+0.5 / w_{5}+1 / w_{6}+0.5 / w_{7}+0 / w_{8}$ $\mathrm{B}_{2.7}=0 / w_{1}+0 / w_{2}+0 / w_{3}+0 / w_{4}+0 / w_{5}+0.5 / w_{6}+1 / w_{7}+0.5 / w_{8}$ $\mathrm{B}_{2.8}=0 / w_{1}+0 / w_{2}+0 / w_{3}+0 / w_{4}+0 / w_{5}+0 / w_{6}+0.5 / w_{7}+1 / w_{8}$

dimana $A_{n}$ mewakili nilai fuzzy set untuk faktor utama dengan jumlah $\mathrm{n}$ sama dengan jumlah kelas faktor utama, dan $B_{i . n}$ melambangkan faktor pendukung dengan $i$ merupakan indeks faktor pendukung dan jumlah $\mathrm{n}$ sama dengan jumlah kelas faktor pendukung.

\section{Fuzzyfikasi Data}

Fuzzyfikasi data dilakukan dengan merubah data historis ke dalam bentuk nilai linguistic fuzzy. Dalam penelitian ini nilai lingustik fuzzy untuk faktor utama dilambangkan dengan $\mathrm{Ai}$, sedangkan kedua faktor pendukung dilambangkan dengan $\mathrm{B}_{1} \mathrm{i}$ dan $\mathrm{B}_{2} \mathrm{i}$ di mana merupakan jumlah interval dan fuzzifikasi data dilakukan dengan mencocokkan nilai data historis masing-masing variabel ke dalam nilai interval. Sehingga, misalkan untuk menentukan fuzzifikasi data untuk tanggal 1 September 2017, data DMA adalah $0.1104 \%$. Data DMA tersebut masuk ke dalam interval u2, sehingga didapat nilai fuzzifikasi untuk data tanggal 1 September 2017 adalah $\mathrm{A}_{2}$, dimana pada fuzzy set $\mathrm{A}_{2}$. Tabel $6,7,8$ menunjukkan hasil fuzzyfikasi data DMA, Inflow, dan Outflow untuk rentang tiga bulan dari 1 September - 1 Desember 2017:

TABEL VI

FUZZYFIKASI DMA

\begin{tabular}{|c|c|c|c|}
\hline Tanggal & Data Aktual (\%) & Interval & Fuzzyfikasi \\
\hline $2017-09-01$ & -0.1104 & $\mathrm{u}_{2}$ & $\mathrm{~A}_{2}$ \\
\hline $2017-09-02$ & -0.1190 & $\mathrm{u}_{2}$ & $\mathrm{~A}_{2}$ \\
\hline $2017-09-03$ & -0.0340 & $\mathrm{u}_{3}$ & $\mathrm{~A}_{3}$ \\
\hline $2017-09-04$ & 0.0170 & $\mathrm{u}_{3}$ & $\mathrm{~A}_{3}$ \\
\hline $2017-09-05$ & -0.0681 & $\mathrm{u}_{2}$ & $\mathrm{~A}_{2}$ \\
\hline$\ldots$ & $\ldots$ & $\ldots$ & $\ldots$ \\
\hline $2017-11-29$ & -0.0621 & $\mathrm{u}_{2}$ & $\mathrm{~A}_{2}$ \\
\hline $2017-11-30$ & -0.1065 & $\mathrm{u}_{2}$ & $\mathrm{~A}_{2}$ \\
\hline $2017-12-01$ & -0.0888 & $\mathrm{u}_{2}$ & $\mathrm{~A}_{2}$ \\
\hline
\end{tabular}

TABEL VII

FUZZYFIKASI INFLOW

\begin{tabular}{|c|c|c|c|}
\hline Tanggal & $\begin{array}{c}\text { Data Aktual } \\
(\%)\end{array}$ & Interval & Fuzzyfikasi \\
\hline $2017-09-01$ & -34.5140 & $v_{7}$ & $\mathrm{~B}_{1 \cdot 7}$ \\
\hline $2017-09-02$ & -63.3479 & $v_{7}$ & $\mathrm{~B}_{1 \cdot 7}$ \\
\hline $2017-09-03$ & 647.4696 & $v_{8}$ & $\mathrm{~B}_{1 \cdot 8}$ \\
\hline $2017-09-04$ & 65.5430 & $v_{7}$ & $\mathrm{~B}_{1 \cdot 7}$ \\
\hline $2017-09-05$ & -50.9537 & $v_{7}$ & $\mathrm{~B}_{1 \cdot 7}$ \\
\hline$\ldots$ & $\ldots$ & $\ldots$ & $\ldots$ \\
\hline $2017-11-29$ & -21.0133 & $v_{7}$ & $\mathrm{~B}_{1 \cdot 7}$ \\
\hline $2017-11-30$ & -56.6451 & $v_{7}$ & $\mathrm{~B}_{1 \cdot 7}$ \\
\hline $2017-12-01$ & 76.7686 & $v_{7}$ & $\mathrm{~B}_{1 \cdot 7}$ \\
\hline
\end{tabular}

TABEL VIII

FUZZYFIKASI OUTFLOW

\begin{tabular}{|c|c|c|c|}
\hline Tanggal & $\begin{array}{c}\text { Data Aktual } \\
(\%)\end{array}$ & Interval & Fuzzyfikasi \\
\hline $2017-09-01$ & 54.8235 & $w_{8}$ & $\mathrm{~B}_{2.8}$ \\
\hline $2017-09-02$ & -8.5551 & $w_{2}$ & $\mathrm{~B}_{2.2}$ \\
\hline $2017-09-03$ & -5.5284 & $w_{3}$ & $\mathrm{~B}_{2.3}$ \\
\hline $2017-09-04$ & 6.3311 & $w_{4}$ & $\mathrm{~B}_{2.4}$ \\
\hline $2017-09-05$ & 7.0527 & $w_{4}$ & $\mathrm{~B}_{2.4}$ \\
\hline$\ldots$ & $\ldots$ & $\ldots$ & $\ldots$ \\
\hline $2017-11-29$ & -11.7548 & $w_{2}$ & $\mathrm{~B}_{2.2}$ \\
\hline $2017-11-30$ & 7.3008 & $w_{4}$ & $\mathrm{~B}_{2.4}$ \\
\hline $2017-12-01$ & 2.2364 & $w_{3}$ & $\mathrm{~B}_{2.3}$ \\
\hline
\end{tabular}

5. Pembentukan Fuzzy Logic Relationship (FLR)

Pembentukan Fuzzy Logic Relationship (FLR) orde ke-n dilakukan dengan menggunakan persamaan bentuk relasi yang dapat dituliskan dengan sebagaimana terdapat pada [7]

$\left(X_{\mathrm{j}-\mathrm{k}} ; Y_{2, \mathrm{j}-\mathrm{k}}, \ldots, Y_{\mathrm{m}-1, \mathrm{j}-\mathrm{k}}\right), \ldots,\left(X_{\mathrm{j}-2} ; Y_{2, \mathrm{j}-2}, \ldots, Y_{\mathrm{m}-1, \mathrm{j}-2}\right),\left(X_{\mathrm{j}-1}\right.$, $\left.Y_{1, \mathrm{j}-1}, Y_{2, \mathrm{j}-1}, \ldots, Y_{\mathrm{m}-1, \mathrm{j}-1}\right) \rightarrow X_{\mathrm{j}} \ldots(9)$

dimana $\mathrm{j}>\mathrm{k}$, dan $\mathrm{Xj}-\mathrm{k}$ menampilkan step ke-k ketergantungan dari nilai ke-j faktor utama. Dimana, $\mathrm{k}$ merupakan jumlah orde dan $\mathrm{j}$ merupakan data waktu sekarang, $\mathrm{X}$ dan dan $\mathrm{Y}$ merupakan faktor utama dan faktor pendukung secara berturut-turut. Fuzzy logic relationship yang terbentuk untuk range data 1 September - 1 Desember 2017 ditunjukkan pada Tabel 9. 
TABEL IX

FUZZY LOGIC RELATIONSHIP (FLR) MASING-MASING ORDE

\begin{tabular}{|c|c|c|c|c|c|c|c|c|c|c|}
\hline \multirow[t]{2}{*}{ Tanggal } & \multicolumn{2}{|l|}{ Orde 1} & \multicolumn{2}{|l|}{ Orde 2} & \multicolumn{2}{|l|}{ Orde 3} & \multicolumn{2}{|l|}{ Orde 4} & \multicolumn{2}{|l|}{ Orde 5} \\
\hline & $(\mathrm{t}-1)$ & $t$ & $(t-2),(t-1)$ & $\mathbf{t}$ & $(t-3),(t-2),(t-1)$ & $t$ & $\begin{array}{c}(\mathrm{t}-4),(\mathrm{t}-3),(\mathrm{t}- \\
2),(\mathrm{t}-1)\end{array}$ & $\mathbf{t}$ & $\begin{array}{l}(\mathrm{t}-5),(\mathrm{t}-4),(\mathrm{t}- \\
3),(\mathrm{t}-2),(\mathrm{t}-1)\end{array}$ & $\mathbf{t}$ \\
\hline 2017-09-01 & & & & & & & & & & \\
\hline 2017-09-02 & $\left(\mathrm{A}_{2}, \mathrm{~B}_{1.7}, \mathrm{~B}_{2.8}\right)$ & $\mathrm{A}_{2}$ & & & & & & & & \\
\hline 2017-09-03 & $\left(\mathrm{A}_{2}, \mathrm{~B}_{1.7}, \mathrm{~B}_{2 \cdot 2}\right)$ & $\mathrm{A}_{3}$ & $\begin{array}{l}\left(\mathrm{A}_{2}, \mathrm{~B}_{1.7}, \mathrm{~B}_{2.2}\right), \\
\left(\mathrm{A}_{2}, \mathrm{~B}_{1.7}, \mathrm{~B}_{2.8}\right)\end{array}$ & $\mathrm{A}_{3}$ & & & & & & \\
\hline 2017-09-04 & $\left(\mathrm{A}_{3}, \mathrm{~B}_{1 \cdot 8}, \mathrm{~B}_{2 \cdot 3}\right)$ & $\mathrm{A}_{3}$ & $\begin{array}{l}\left(\mathrm{A}_{3}, \mathrm{~B}_{1 \cdot 8}, \mathrm{~B}_{2 \cdot 3}\right), \\
\left(\mathrm{A}_{2}, \mathrm{~B}_{1 \cdot 7}, \mathrm{~B}_{2 \cdot 2}\right)\end{array}$ & $\mathrm{A}_{3}$ & $\begin{array}{l}\left(\mathrm{A}_{3}, \mathrm{~B}_{1.8}, \mathrm{~B}_{2.3}\right), \\
\left(\mathrm{A}_{2}, \mathrm{~B}_{1.7}, \mathrm{~B}_{2.2}\right), \\
\left(\mathrm{A}_{2}, \mathrm{~B}_{1.7}, \mathrm{~B}_{2.8}\right)\end{array}$ & $\mathrm{A}_{3}$ & & & & \\
\hline 2017-09-05 & $\left(\mathrm{A}_{3}, \mathrm{~B}_{1 \cdot 7}, \mathrm{~B}_{2 \cdot 4}\right)$ & $\mathrm{A}_{2}$ & $\begin{array}{l}\left(\mathrm{A}_{3}, \mathrm{~B}_{1 \cdot 7}, \mathrm{~B}_{2 \cdot 4}\right), \\
\left(\mathrm{A}_{3}, \mathrm{~B}_{1.8}, \mathrm{~B}_{2 \cdot 3}\right)\end{array}$ & $\mathrm{A}_{2}$ & $\begin{array}{l}\left(\mathrm{A}_{3}, \mathrm{~B}_{1 \cdot 7}, \mathrm{~B}_{2 \cdot 4}\right), \\
\left(\mathrm{A}_{3}, \mathrm{~B}_{1.8}, \mathrm{~B}_{2 \cdot 3}\right), \\
\left(\mathrm{A}_{2}, \mathrm{~B}_{1 \cdot 7}, \mathrm{~B}_{2 \cdot 2}\right)\end{array}$ & $\mathrm{A}_{2}$ & $\begin{array}{c}\left(\mathrm{A}_{3}, \mathrm{~B}_{1 \cdot 7}, \mathrm{~B}\right. \\
2.4),\left(\mathrm{A}_{3}, \mathrm{~B}_{1.8},\right. \\
\left.\mathrm{B}_{2.3}\right),\left(\mathrm{A}_{2}, \mathrm{~B}\right. \\
\left.1.7, \mathrm{~B}_{2.2}\right),\left(\mathrm{A}_{2},\right. \\
\left.\mathrm{B}_{1.7}, \mathrm{~B}_{2.8}\right)\end{array}$ & $\mathrm{A}_{2}$ & & \\
\hline 2017-09-06 & $\left(\mathrm{A}_{2}, \mathrm{~B}_{1.7}, \mathrm{~B}_{2.4}\right)$ & $\mathrm{A}_{2}$ & $\begin{array}{l}\left(\mathrm{A}_{2}, \mathrm{~B}_{1.7}, \mathrm{~B}_{2.4}\right), \\
\left(\mathrm{A}_{3}, \mathrm{~B}_{1.7}, \mathrm{~B}_{2.4}\right)\end{array}$ & $\mathrm{A}_{2}$ & $\begin{array}{l}\left(\mathrm{A}_{2}, \mathrm{~B}_{1.7}, \mathrm{~B}_{2.4}\right), \\
\left(\mathrm{A}_{3}, \mathrm{~B}_{1.7}, \mathrm{~B}_{2 \cdot 4}\right), \\
\left(\mathrm{A}_{3}, \mathrm{~B}_{1.8}, \mathrm{~B}_{2.3}\right)\end{array}$ & $\mathrm{A}_{2}$ & $\begin{array}{c}\left(\mathrm{A}_{2}, \mathrm{~B}_{1 \cdot 7.7}, \mathrm{~B}\right. \\
2.4),\left(\mathrm{A}_{3}, \mathrm{~B}_{1 \cdot 7},\right. \\
\left.\mathrm{B}_{2 \cdot 4}\right),\left(\mathrm{A}_{3}, \mathrm{~B}\right. \\
\left.1 \cdot 8, \mathrm{~B}_{2 \cdot 3}\right),\left(\mathrm{A}_{2},\right. \\
\left.\mathrm{B}_{1.7}, \mathrm{~B}_{2 \cdot 2}\right)\end{array}$ & $\mathrm{A}_{2}$ & $\begin{array}{c}\left(\mathrm{A}_{2}, \mathrm{~B}_{1 \cdot 7}, \mathrm{~B}\right. \\
2.4),\left(\mathrm{A}_{3}, \mathrm{~B}_{1.7},\right. \\
\mathrm{B}_{2 \cdot 4},\left(\mathrm{~A}_{3}, \mathrm{~B}\right. \\
\left.{ }_{1.8}, \mathrm{~B}_{2 \cdot 3}\right),\left(\mathrm{A}_{2},\right. \\
\left.\mathrm{B}_{1.7}, \mathrm{~B}_{2 \cdot 2}\right), \\
\left(\mathrm{A}_{2}, \mathrm{~B}_{1.7}, \mathrm{~B}\right. \\
2.8) \\
\end{array}$ & $\mathrm{A}_{2}$ \\
\hline$\ldots$ & $\ldots$ & $\ldots$ & $\ldots$ & $\ldots$ & $\ldots$ & $\ldots$ & $\ldots$ & $\ldots$ & $\ldots$ & $\ldots$ \\
\hline$\ldots$ & $\ldots$ & $\cdots$ & $\ldots$ & $\ldots$ & $\ldots$ & $\cdots$ & $\ldots$ & $\cdots$ & $\ldots$ & $\cdots$ \\
\hline $2017-11-30$ & $\left(\mathrm{~A}_{2}, \mathrm{~B}_{1 \cdot 7}, \mathrm{~B}_{2 \cdot 2}\right)$ & $\mathrm{A}_{2}$ & $\begin{array}{l}\left(\mathrm{A}_{2}, \mathrm{~B}_{1 \cdot 7}, \mathrm{~B}_{2 \cdot 2}\right), \\
\left(\mathrm{A}_{2}, \mathrm{~B}_{1 \cdot 7}, \mathrm{~B}_{2 \cdot 4}\right)\end{array}$ & $\mathrm{A}_{2}$ & $\begin{array}{l}\left(\mathrm{A}_{2}, \mathrm{~B}_{1 \cdot 7}, \mathrm{~B}_{2 \cdot 2}\right), \\
\left(\mathrm{A}_{2}, \mathrm{~B}_{1 \cdot 7}, \mathrm{~B}_{2 \cdot 4}\right), \\
\left(\mathrm{A}_{2}, \mathrm{~B}_{1 \cdot 7}, \mathrm{~B}_{2 \cdot 3}\right)\end{array}$ & $\mathrm{A}_{2}$ & $\begin{array}{c}\left(\mathrm{A}_{2}, \mathrm{~B}_{1.7}, \mathrm{~B}\right. \\
2.2),\left(\mathrm{A}_{2}, \mathrm{~B}_{1.7},\right. \\
\left.\mathrm{B}_{2.4}\right),\left(\mathrm{A}_{2}, \mathrm{~B}\right. \\
\left.1.7, \mathrm{~B}_{2.3}\right),\left(\mathrm{A}_{2},\right. \\
\left.\mathrm{B}_{1.7}, \mathrm{~B}_{2.4}\right)\end{array}$ & $\mathrm{A}_{2}$ & $\begin{array}{c}\left(\mathrm{A}_{2}, \mathrm{~B}_{1 \cdot 7}, \mathrm{~B}\right. \\
2.2),\left(\mathrm{A}_{2}, \mathrm{~B}_{1 \cdot 7},\right. \\
\left.\mathrm{B}_{2.4}\right),\left(\mathrm{A}_{2}, \mathrm{~B}\right. \\
\left.{ }_{1.7}, \mathrm{~B}_{2 \cdot 3}\right),\left(\mathrm{A}_{2},\right. \\
\left.\mathrm{B}_{1.7}, \mathrm{~B}_{2.4}\right), \\
\left(\mathrm{A}_{3}, \mathrm{~B}_{1.7}, \mathrm{~B}\right. \\
2.3)\end{array}$ & $\mathrm{A}_{2}$ \\
\hline 2017-12-01 & $\left(\mathrm{A}_{2}, \mathrm{~B}_{1 \cdot 7}, \mathrm{~B}_{2 \cdot 4}\right)$ & $\mathrm{A}_{2}$ & $\begin{array}{l}\left(\mathrm{A}_{2}, \mathrm{~B}_{1 \cdot 7}, \mathrm{~B}_{2 \cdot 4}\right), \\
\left(\mathrm{A}_{2}, \mathrm{~B}_{1 \cdot 7}, \mathrm{~B}_{2 \cdot 2}\right)\end{array}$ & $\mathrm{A}_{2}$ & $\begin{array}{l}\left(\mathrm{A}_{2}, \mathrm{~B}_{1 \cdot 7}, \mathrm{~B}_{2 \cdot 4}\right), \\
\left(\mathrm{A}_{2}, \mathrm{~B}_{1 \cdot 7}, \mathrm{~B}_{2 \cdot 2}\right), \\
\left(\mathrm{A}_{2}, \mathrm{~B}_{1 \cdot 7}, \mathrm{~B}_{2 \cdot 4}\right)\end{array}$ & $\mathrm{A}_{2}$ & $\begin{array}{c}\left(\mathrm{A}_{2}, \mathrm{~B}_{1 \cdot 7}, \mathrm{~B}\right. \\
2 \cdot 4),\left(\mathrm{A}_{2}, \mathrm{~B}_{1 \cdot 7},\right. \\
\left.\mathrm{B}_{2 \cdot 2}\right),\left(\mathrm{A}_{2}, \mathrm{~B}\right. \\
\left.{ }_{1.7}, \mathrm{~B}_{2 \cdot 4}\right),\left(\mathrm{A}_{2},\right. \\
\left.\mathrm{B}_{1.7}, \mathrm{~B}_{2 \cdot 3}\right)\end{array}$ & $\mathrm{A}_{2}$ & $\begin{array}{c}\left(\mathrm{A}_{2}, \mathrm{~B}_{1 \cdot 7}, \mathrm{~B}\right. \\
2 \cdot 4),\left(\mathrm{A}_{2}, \mathrm{~B}_{1 \cdot 7},\right. \\
\left.\mathrm{B}_{2 \cdot 2}\right),\left(\mathrm{A}_{2}, \mathrm{~B}\right. \\
\left.1.7, \mathrm{~B}_{2 \cdot 4}\right),\left(\mathrm{A}_{2},\right. \\
\left.\mathrm{B}_{1.7}, \mathrm{~B}_{2 \cdot 3}\right), \\
\left(\mathrm{A}_{2}, \mathrm{~B}_{1 \cdot 7}, \mathrm{~B}\right. \\
2.4) \\
\end{array}$ & $\mathrm{A}_{2}$ \\
\hline
\end{tabular}

6. Pembentukan Fuzzy Logic Relationship Group (FLRG)

Pembentukan fuzzy logic relationship group dilakukan berdasarkan hasil dari pendefinisian FLR untuk masing-masing data. Pembentukan FLRG dilakukan berdasarkan nilai ruas sebelah kiri FLR, yakni bagian yang menunjukkan fuzzifikasi data ke t-k, yang memiliki nilai yang sama. Apabila nilai ruas sebelah kiri FLR memiliki nilai yang sama, maka mereka akan dikelompokkan menjadi satu kelompok. Apabila sebuah fuzzy set memiliki lebih dari satu hubungan terhadap data ke-t yang ditunjukkan pada ruas sebelah kanan FLR, maka fuzzy set tersebut tetap dianggap satu kelompok yang memiliki lebih dari satu relasi. Fuzzy set yang masih memiliki lebih dari satu hubungan terhadap data ke-t

dianggap sebagai FLRG yang masih memiliki ambiguitas, karena memiliki lebih dari satu relasi. FLRG yang terbentuk untuk range data 1 September 1 Desember 2017 ditunjukkan pada Tabel 10-14.
TABEL X

FLRG ORDE 1

\begin{tabular}{|c|c|c|}
\hline Group & $\mathrm{t}-1$ & $\mathrm{t}$ \\
\hline 1 & $\left(\mathrm{~A}_{2}, \mathrm{~B}_{1 \cdot 1}, \mathrm{~B}_{2 \cdot 4}\right)$ & $\mathrm{A}_{2}$ \\
\hline 2 & $\left(\mathrm{~A}_{2}, \mathrm{~B}_{1 \cdot 7}, \mathrm{~B}_{2 \cdot 1}\right)$ & $\mathrm{A}_{2}$ \\
\hline$\ldots$ & $\ldots$ & $\ldots$ \\
\hline$\ldots$ & $\ldots$ & $\ldots$ \\
\hline 20 & $\left(\mathrm{~A}_{5}, \mathrm{~B}_{1 \cdot 8}, \mathrm{~B}_{2 \cdot 4}\right)$ & $\mathrm{A}_{5}$ \\
\hline 21 & $\left(\mathrm{~A}_{6}, \mathrm{~B}_{1 \cdot 8}, \mathrm{~B}_{2 \cdot 2}\right)$ & $\mathrm{A}_{3}$ \\
\hline 22 & $\left(\mathrm{~A}_{8}, \mathrm{~B}_{1 \cdot 8}, \mathrm{~B}_{2 \cdot 3}\right)$ & $\mathrm{A}_{3}$ \\
\hline
\end{tabular}

TABEL XI

FLRG ORDE 2

\begin{tabular}{|c|c|c|}
\hline Group & $(\mathrm{t}-2),(\mathrm{t}-1)$ & $\mathrm{t}$ \\
\hline 1 & $\left(\mathrm{~A}_{2}, \mathrm{~B}_{1 \cdot 1}, \mathrm{~B}_{2 \cdot 4}\right),\left(\mathrm{A}_{2}, \mathrm{~B}_{1 \cdot 7}, \mathrm{~B}_{2 \cdot 5}\right)$ & $\mathrm{A}_{2}$ \\
\hline 2 & $\left(\mathrm{~A}_{2}, \mathrm{~B}_{1 \cdot 7}, \mathrm{~B}_{2 \cdot 1}\right),\left(\mathrm{A}_{2}, \mathrm{~B}_{1 \cdot 7}, \mathrm{~B}_{2 \cdot 3}\right)$ & $\mathrm{A}_{2}$ \\
\hline 3 & $\left(\mathrm{~A}_{2}, \mathrm{~B}_{1 \cdot 7}, \mathrm{~B}_{2 \cdot 2}\right),\left(\mathrm{A}_{2}, \mathrm{~B}_{1 \cdot 7}, \mathrm{~B}_{2 \cdot 2}\right)$ & $\mathrm{A}_{2}$ \\
\hline 4 & $\left(\mathrm{~A}_{2}, \mathrm{~B}_{1 \cdot 7}, \mathrm{~B}_{2 \cdot 2}\right),\left(\mathrm{A}_{2}, \mathrm{~B}_{1 \cdot 7}, \mathrm{~B}_{2 \cdot 3}\right)$ & $\mathrm{A}_{2}$ \\
\hline 5 & $\left(\mathrm{~A}_{2}, \mathrm{~B}_{1 \cdot 7}, \mathrm{~B}_{2 \cdot 2}\right),\left(\mathrm{A}_{2}, \mathrm{~B}_{1 \cdot 7}, \mathrm{~B}_{2 \cdot 4}\right)$ & $\mathrm{A}_{2}$ \\
\hline$\ldots$ & $\ldots$ & $\ldots$ \\
\hline 51 & $\left(\mathrm{~A}_{5}, \mathrm{~B}_{1 \cdot 8}, \mathrm{~B}_{2 \cdot 4}\right),\left(\mathrm{A}_{2}, \mathrm{~B}_{1 \cdot 7}, \mathrm{~B}_{2 \cdot 8}\right)$ & $\mathrm{A}_{5}$ \\
\hline 52 & $\left(\mathrm{~A}_{6}, \mathrm{~B}_{1 \cdot 8}, \mathrm{~B}_{2 \cdot 2}\right),\left(\mathrm{A}_{2}, \mathrm{~B}_{1 \cdot 7}, \mathrm{~B}_{2 \cdot 3}\right)$ & $\mathrm{A}_{3}$ \\
\hline 53 & $\left(\mathrm{~A}_{8}, \mathrm{~B}_{1 \cdot 8}, \mathrm{~B}_{2 \cdot 3}\right),\left(\mathrm{A}_{3}, \mathrm{~B}_{1 \cdot 7}, \mathrm{~B}_{2 \cdot 3}\right)$ & $\mathrm{A}_{3}$ \\
\hline
\end{tabular}


TABEL XII

FLRG ORDE 3

\begin{tabular}{|c|c|c|}
\hline Group & $(t-3),(t-2),(t-1)$ & $\mathrm{t}$ \\
\hline 1 & $\begin{array}{c}\left(\mathrm{A}_{2}, \mathrm{~B}_{1 \cdot 1}, \mathrm{~B}_{2 \cdot 4}\right),\left(\mathrm{A}_{2}, \mathrm{~B}_{1 \cdot 7}, \mathrm{~B}_{2 \cdot 5}\right),\left(\mathrm{A}_{2}, \mathrm{~B}_{1 \cdot 7},\right. \\
\left.\mathrm{B}_{2 \cdot 1}\right)\end{array}$ & $\mathrm{A}_{2}$ \\
\hline 2 & $\begin{array}{c}\left(\mathrm{A}_{2}, \mathrm{~B}_{1 \cdot 7}, \mathrm{~B}_{2 \cdot 1}\right),\left(\mathrm{A}_{2}, \mathrm{~B}_{1 \cdot 7}, \mathrm{~B}_{2 \cdot 3}\right),\left(\mathrm{A}_{2}, \mathrm{~B}_{1 \cdot 7},\right. \\
\left.\mathrm{B}_{2 \cdot 3}\right)\end{array}$ & $\mathrm{A}_{2}$ \\
\hline 3 & $\begin{array}{c}\left(\mathrm{A}_{2}, \mathrm{~B}_{1 \cdot 7}, \mathrm{~B}_{2 \cdot 2}\right),\left(\mathrm{A}_{2}, \mathrm{~B}_{1 \cdot 7}, \mathrm{~B}_{2 \cdot 2}\right),\left(\mathrm{A}_{2}, \mathrm{~B}_{1 \cdot 7},\right. \\
\left.\mathrm{B}_{2 \cdot 3}\right)\end{array}$ & $\mathrm{A}_{2}$ \\
\hline 4 & $\begin{array}{c}\left(\mathrm{A}_{2}, \mathrm{~B}_{1 \cdot 7}, \mathrm{~B}_{2 \cdot 2}\right),\left(\mathrm{A}_{2}, \mathrm{~B}_{1 \cdot 7}, \mathrm{~B}_{2 \cdot 3}\right),\left(\mathrm{A}_{2}, \mathrm{~B}_{1 \cdot 7},\right. \\
\left.\mathrm{B}_{2 \cdot 3}\right)\end{array}$ & $\mathrm{A}_{2}$ \\
\hline 5 & $\begin{array}{c}\left(\mathrm{A}_{2}, \mathrm{~B}_{1 \cdot 7}, \mathrm{~B}_{2 \cdot 2}\right),\left(\mathrm{A}_{2}, \mathrm{~B}_{1 \cdot 7}, \mathrm{~B}_{2 \cdot 3}\right),\left(\mathrm{A}_{2}, \mathrm{~B}_{1 \cdot 7},\right. \\
\left.\mathrm{B}_{2 \cdot 4}\right)\end{array}$ & $\mathrm{A}_{2}$ \\
\hline$\ldots$ & $\ldots$ & $\ldots$ \\
\hline 72 & $\begin{array}{c}\left(\mathrm{A}_{5}, \mathrm{~B}_{1 \cdot 8}, \mathrm{~B}_{2 \cdot 4}\right),\left(\mathrm{A}_{2}, \mathrm{~B}_{1 \cdot 7}, \mathrm{~B}_{2 \cdot 8}\right),\left(\mathrm{A}_{3}, \mathrm{~B}_{1 \cdot 7},\right. \\
\left.\mathrm{B}_{2 \cdot 1}\right)\end{array}$ & $\mathrm{A}_{5}$ \\
\hline 73 & $\begin{array}{c}\left(\mathrm{A}_{6}, \mathrm{~B}_{1 \cdot 8}, \mathrm{~B}_{2 \cdot 2}\right),\left(\mathrm{A}_{2}, \mathrm{~B}_{1 \cdot 7}, \mathrm{~B}_{2 \cdot 3}\right),\left(\mathrm{A}_{2}, \mathrm{~B}_{1 \cdot 7},\right. \\
\left.\mathrm{B}_{2 \cdot 3}\right)\end{array}$ & $\mathrm{A}_{3}$ \\
\hline 74 & $\begin{array}{c}\left(\mathrm{A}_{8}, \mathrm{~B}_{1 \cdot 8}, \mathrm{~B}_{2 \cdot 3}\right),\left(\mathrm{A}_{3}, \mathrm{~B}_{1 \cdot 7}, \mathrm{~B}_{2 \cdot 3}\right),\left(\mathrm{A}_{4}, \mathrm{~B}_{1 \cdot 7},\right. \\
\left.\mathrm{B}_{2 \cdot 4}\right)\end{array}$ & $\mathrm{A}_{3}$ \\
\hline
\end{tabular}

TABEL XIII

FLRG ORDE 4

\begin{tabular}{|c|c|c|}
\hline Group & $(\mathrm{t}-4),(\mathrm{t}-3),(\mathrm{t}-2),(\mathrm{t}-1)$ & $\mathrm{t}$ \\
\hline 1 & $\left(\mathrm{~A}_{2}, \mathrm{~B}_{1 \cdot 1}, \mathrm{~B}_{2 \cdot 4}\right),\left(\mathrm{A}_{2}, \mathrm{~B}_{1 \cdot 7}, \mathrm{~B}_{2 \cdot 5}\right),\left(\mathrm{A}_{2}, \mathrm{~B}_{1 \cdot 7}\right.$, & $\mathrm{A}_{2}$ \\
& $\left.\mathrm{~B}_{2 \cdot 1}\right),\left(\mathrm{A}_{2}, \mathrm{~B}_{1 \cdot 7}, \mathrm{~B}_{2 \cdot 3}\right)$ & \\
\hline 2 & $\left(\mathrm{~A}_{2}, \mathrm{~B}_{1 \cdot 7}, \mathrm{~B}_{2 \cdot 1}\right),\left(\mathrm{A}_{2}, \mathrm{~B}_{1 \cdot 7}, \mathrm{~B}_{2 \cdot 3}\right),\left(\mathrm{A}_{2}, \mathrm{~B}_{1 \cdot 7}\right.$, & $\mathrm{A}_{2}$ \\
& $\left.\mathrm{~B}_{2 \cdot 3}\right),\left(\mathrm{A}_{2}, \mathrm{~B}_{1 \cdot 7}, \mathrm{~B}_{2 \cdot 5}\right)$ & \\
\hline 3 & $\left(\mathrm{~A}_{2}, \mathrm{~B}_{1 \cdot 7}, \mathrm{~B}_{2 \cdot 2}\right),\left(\mathrm{A}_{2}, \mathrm{~B}_{1 \cdot 7}, \mathrm{~B}_{2 \cdot 2}\right),\left(\mathrm{A}_{2}, \mathrm{~B}_{1 \cdot 7}\right.$, & $\mathrm{A}_{2}$ \\
& $\left.\mathrm{~B}_{2 \cdot 3}\right),\left(\mathrm{A}_{2}, \mathrm{~B}_{1 \cdot 7}, \mathrm{~B}_{2 \cdot 4}\right)$ & \\
\hline 4 & $\left(\mathrm{~A}_{2}, \mathrm{~B}_{1 \cdot 7}, \mathrm{~B}_{2 \cdot 2}\right),\left(\mathrm{A}_{2}, \mathrm{~B}_{1 \cdot 7}, \mathrm{~B}_{2 \cdot 3}\right),\left(\mathrm{A}_{2}, \mathrm{~B}_{1 \cdot 7}\right.$, & $\mathrm{A}_{2}$ \\
& $\left.\mathrm{~B}_{2 \cdot 3}\right),\left(\mathrm{A}_{2}, \mathrm{~B}_{1 \cdot 7}, \mathrm{~B}_{2 \cdot 4}\right)$ & $\ldots$ \\
\hline$\ldots$ & $\ldots$ & $\ldots$ \\
\hline$\ldots$ & $\ldots$ & $\mathrm{A}_{5}$ \\
\hline 80 & $\left(\mathrm{~A}_{5}, \mathrm{~B}_{1 \cdot 8}, \mathrm{~B}_{2 \cdot 4}\right),\left(\mathrm{A}_{2}, \mathrm{~B}_{1 \cdot 7}, \mathrm{~B}_{2 \cdot 8}\right),\left(\mathrm{A}_{3}, \mathrm{~B}_{1 \cdot 7}\right.$, & \\
\hline 81 & $\left(\mathrm{~B}_{2 \cdot 1}, \mathrm{~B}_{1 \cdot 8}, \mathrm{~B}_{2 \cdot 2}\right),\left(\mathrm{A}_{2}, \mathrm{~B}_{1 \cdot 8}, \mathrm{~B}_{2 \cdot 7}, \mathrm{~B}_{2 \cdot 3}\right),\left(\mathrm{A}_{2}, \mathrm{~B}_{1 \cdot 7}\right.$, & $\mathrm{A}_{3}$ \\
\hline 82 & $\left.\mathrm{~B}_{2 \cdot 3}\right),\left(\mathrm{A}_{2}, \mathrm{~B}_{1 \cdot 7}, \mathrm{~B}_{2 \cdot 2}\right)$ & \\
\hline & $\left(\mathrm{A}_{8}, \mathrm{~B}_{1 \cdot 8}, \mathrm{~B}_{2 \cdot 3}\right),\left(\mathrm{A}_{3}, \mathrm{~B}_{1 \cdot 7}, \mathrm{~B}_{2 \cdot 3}\right),\left(\mathrm{A}_{4}, \mathrm{~B}_{1 \cdot 7}\right.$, & $\mathrm{A}_{3}$ \\
& $\left.\mathrm{~B}_{2 \cdot 4}\right),\left(\mathrm{A}_{3}, \mathrm{~B}_{1 \cdot 7}, \mathrm{~B}_{2 \cdot 2}\right)$ & \\
\hline
\end{tabular}

TABEL XIV

FLRG ORDE 5

\begin{tabular}{|c|c|c|}
\hline Group & $(\mathrm{t}-5),(\mathrm{t}-4),(\mathrm{t}-3),(\mathrm{t}-2),(\mathrm{t}-1)$ & $\mathrm{t}$ \\
\hline 1 & $\left(\mathrm{~A}_{2}, \mathrm{~B}_{1 \cdot 1}, \mathrm{~B}_{2 \cdot 4}\right),\left(\mathrm{A}_{2}, \mathrm{~B}_{1 \cdot 7}, \mathrm{~B}_{2 \cdot 5}\right),\left(\mathrm{A}_{2}, \mathrm{~B}_{1 \cdot 7}\right.$, & $\mathrm{A}_{2}$ \\
& $\left.\mathrm{~B}_{2 \cdot 1}\right),\left(\mathrm{A}_{2}, \mathrm{~B}_{1 \cdot 7}, \mathrm{~B}_{2 \cdot 3}\right),\left(\mathrm{A}_{2}, \mathrm{~B}_{1 \cdot 7}, \mathrm{~B}_{2 \cdot 3}\right)$ & \\
\hline 2 & $\left(\mathrm{~A}_{2}, \mathrm{~B}_{1 \cdot 7}, \mathrm{~B}_{2 \cdot 1}\right),\left(\mathrm{A}_{2}, \mathrm{~B}_{1 \cdot 7}, \mathrm{~B}_{2 \cdot 3}\right),\left(\mathrm{A}_{2}, \mathrm{~B}_{1 \cdot 7}\right.$, & $\mathrm{A}_{2}$ \\
& $\left.\mathrm{~B}_{2 \cdot 3}\right),\left(\mathrm{A}_{2}, \mathrm{~B}_{1 \cdot 7}, \mathrm{~B}_{2 \cdot 5}\right),\left(\mathrm{A}_{2}, \mathrm{~B}_{1 \cdot 7}, \mathrm{~B}_{2 \cdot 3}\right)$ & \\
\hline 3 & $\left(\mathrm{~A}_{2}, \mathrm{~B}_{1 \cdot 7}, \mathrm{~B}_{2 \cdot 2}\right),\left(\mathrm{A}_{2}, \mathrm{~B}_{1 \cdot 7}, \mathrm{~B}_{2 \cdot 2}\right),\left(\mathrm{A}_{2}, \mathrm{~B}_{1 \cdot 7}\right.$, & $\mathrm{A}_{2}$ \\
& $\left.\mathrm{~B}_{2 \cdot 3}\right),\left(\mathrm{A}_{2}, \mathrm{~B}_{1 \cdot 7}, \mathrm{~B}_{2 \cdot 4}\right),\left(\mathrm{A}_{2}, \mathrm{~B}_{1 \cdot 7}, \mathrm{~B}_{2 \cdot 2}\right)$ & \\
\hline 4 & $\left(\mathrm{~A}_{2}, \mathrm{~B}_{1 \cdot 7}, \mathrm{~B}_{2 \cdot 2}\right),\left(\mathrm{A}_{2}, \mathrm{~B}_{1 \cdot 7}, \mathrm{~B}_{2 \cdot 3}\right),\left(\mathrm{A}_{2}, \mathrm{~B}_{1 \cdot 7}\right.$, & $\mathrm{A}_{2}$ \\
& $\left.\mathrm{~B}_{2 \cdot 3}\right),\left(\mathrm{A}_{2}, \mathrm{~B}_{1 \cdot 7}, \mathrm{~B}_{2 \cdot 4}\right),\left(\mathrm{A}_{2}, \mathrm{~B}_{1 \cdot 7}, \mathrm{~B}_{2 \cdot 3}\right)$ & \\
\hline 5 & $\left(\mathrm{~A}_{2}, \mathrm{~B}_{1 \cdot 7}, \mathrm{~B}_{2 \cdot 2}\right),\left(\mathrm{A}_{2}, \mathrm{~B}_{1 \cdot 7}, \mathrm{~B}_{2 \cdot 3}\right),\left(\mathrm{A}_{2}, \mathrm{~B}_{1 \cdot 7}\right.$, & $\mathrm{A}_{2}$ \\
& $\left.\mathrm{~B}_{2 \cdot 4}\right),\left(\mathrm{A}_{2}, \mathrm{~B}_{1 \cdot 7}, \mathrm{~B}_{2 \cdot 2}\right),\left(\mathrm{A}_{2}, \mathrm{~B}_{1 \cdot 7}, \mathrm{~B}_{2 \cdot 4}\right)$ & \\
\hline$\ldots$ & $\ldots$ & $\ldots$ \\
\hline 83 & $\left(\mathrm{~A}_{5}, \mathrm{~B}_{1 \cdot 8}, \mathrm{~B}_{2 \cdot 4}\right),\left(\mathrm{A}_{2}, \mathrm{~B}_{1 \cdot 7}, \mathrm{~B}_{2 \cdot 8}\right),\left(\mathrm{A}_{3}, \mathrm{~B}_{1 \cdot 7}\right.$, & $\mathrm{A}_{5}$ \\
\hline 84 & $\left.\mathrm{~B}_{2 \cdot 1}\right),\left(\mathrm{A}_{6}, \mathrm{~B}_{1 \cdot 8}, \mathrm{~B}_{2 \cdot 2}\right),\left(\mathrm{A}_{2}, \mathrm{~B}_{1 \cdot 7}, \mathrm{~B}_{2 \cdot 3}\right)$ & \\
\hline & $\left(\mathrm{A}_{6}, \mathrm{~B}_{1 \cdot 8}, \mathrm{~B}_{2 \cdot 2}\right),\left(\mathrm{A}_{2}, \mathrm{~B}_{1 \cdot 7}, \mathrm{~B}_{2 \cdot 3}\right),\left(\mathrm{A}_{2}, \mathrm{~B}_{1 \cdot 7}\right.$, & $\mathrm{A}_{3}$ \\
\hline 85 & $\left.\mathrm{~B}_{2 \cdot 3}\right),\left(\mathrm{A}_{2}, \mathrm{~B}_{1 \cdot 7}, \mathrm{~B}_{2 \cdot 2}\right),\left(\mathrm{A}_{2}, \mathrm{~B}_{1 \cdot 7}, \mathrm{~B}_{2 \cdot 3}\right)$ & \\
\hline & $\left(\mathrm{A}_{8}, \mathrm{~B}_{1 \cdot 8}, \mathrm{~B}_{2 \cdot 3}\right),\left(\mathrm{A}_{3}, \mathrm{~B}_{1 \cdot 7}, \mathrm{~B}_{2 \cdot 3}\right),\left(\mathrm{A}_{4}, \mathrm{~B}_{1 \cdot 7}\right.$, & $\mathrm{A}_{3}$ \\
& $\left.\mathrm{~B}_{2 \cdot 4}\right),\left(\mathrm{A}_{3}, \mathrm{~B}_{1 \cdot 7}, \mathrm{~B}_{2 \cdot 2}\right),\left(\mathrm{A}_{2}, \mathrm{~B}_{1 \cdot 7}, \mathrm{~B}_{2 \cdot 3}\right)$ & \\
\hline
\end{tabular}

7. Menghitung Hasil Prediksi

Sebagai contoh apabila ingin memprediksi DMA untuk tangal 1 Desember 2017 pada orde 2, dengan menggunakan rentang data sebanyak 3 bulan dari tanggal 1 September - 1 Desember 2017, maka perhitungan DMA diperoleh dengan mencari nilai FLR untuk tanggal 1 Desember 2017. Data aktual pada tanggal 1 Desember 2017 adalah 56.240 dan nilai persentasenya adalah $-0.0888 \%$. Data tersebut berada pada range [-0.125, -0.005$]$, sehingga termasuk pada interval $\mathrm{u}_{2}$ dengan nilai fuzzifikasi $\mathrm{A}_{2}$. Jika ditelusuri, maka FLR untuk orde 2 pada tanggal 1 Desember 2017 berdasarkan Tabel 9 adalah:

Orde $2:\left(\mathrm{A}_{2}, \mathrm{~B}_{1.7}, \mathrm{~B}_{2.4}\right),\left(\mathrm{A}_{2}, \mathrm{~B}_{1.7}, \mathrm{~B}_{2.2}\right) \rightarrow \mathrm{A}_{2}$

Setelah mendapatkan nilai FLR untuk masingmasing order, maka langkah selanjutnya untuk menghitung prediksi DMA adalah mencari nilai FLRG yang sama dengan ruas kiri FLR. Pada penelitian ini, didapatkan nilai FLRG berdasarkan Tabel 11, untuk orde 2 adalah sebagai berikut:

Orde 2

Grup $16:\left(\mathrm{A}_{2}, \mathrm{~B}_{1.7}, \mathrm{~B}_{2.4}\right),\left(\mathrm{A}_{2}, \mathrm{~B}_{1.7}, \mathrm{~B}_{2.2}\right) \rightarrow \mathrm{A}_{2}$

Setelah didapatkan hasil FLRG, maka dapat dilakukan perhitungan hasil prediksi DMA dengan menggunakan prinsip Multivariate High Order Fuzzy time series, pada prediksi orde 2 dilakukan dengan menggunakan prinsip 1, karena fuzzy set pada FLRG hanya memiliki satu relasi ke fuzzy set lain. Sehingga, hasil prediksi DMA untuk 1 Desember dihitung dengan menggunakan persamaan:

$$
t_{j}=\left\{\begin{array}{cc}
\frac{m_{1}+0,5 m_{2}}{1+0,5}, & j i k a j=1 \\
\frac{0,5 m_{j-1}+m_{j}+0,5 m_{j+1}}{0,5+1+0,5} & , j i k a 2 \leq j \leq n-1 \\
\frac{0,5 m_{n-1}+m_{n}}{0,5+1} & , j i k a j=n
\end{array}\right.
$$

Sehingga, perhitungan prediksi perubahan persentase DMA untuk 1 Desember 2017 pada orde 2 adalah:

$\mathrm{t}_{2}=\left(0.5 \times \mathrm{m}_{1}+\mathrm{m}_{2}+0.5 \mathrm{x} \mathrm{m}_{3}\right) /(0.5+1+0.5)$

$\mathrm{t}_{2}=(0.5 \times(-0.1625)+(-0.0875)+0.5 \times(0.0125)) /$ $(0.5+1+0.5)$

$\mathrm{t}_{2}=-0.0875 \%$

Hasil prediksi tersebut kemudian akan diubah menjadi nilai data aktual, sehingga didapat hasil prediksi DMA untuk 1 Desember 2017 pada orde 2 adalah $56.241 \mathrm{~cm}$. Tabel 15 menunjukkan hasil prediksi DMA dari $1-31$ Desember dengan Multivariate High Order Fuzzy Time Series untuk rentang waktu 3 bulan dan menunjukkan nilai eror dengan menggunakan perhitungan MAPE [12] dengan persamaan

$$
\text { MAPE }=\left[\frac{\frac{\Sigma\left|A_{i}-F_{i}\right|}{A_{i}}}{n}\right] \times 100 \%
$$


TABEL XV

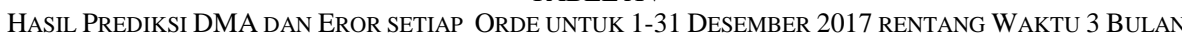

\begin{tabular}{|c|c|c|c|c|c|c|c|c|c|c|c|}
\hline \multirow{2}{*}{ Tanggal } & \multirow{2}{*}{$\begin{array}{c}\text { Data } \\
\text { Aktual }\end{array}$} & \multicolumn{5}{|c|}{ Hasil Prediksi } & \multicolumn{5}{|c|}{ Eror $(\%)$} \\
\hline & & Orde 1 & Orde 2 & Orde 3 & Orde 4 & Orde 5 & Orde 1 & Orde 2 & Orde 3 & Orde 4 & Orde 5 \\
\hline $1 / 12 / 2017$ & 56,240 & 56.2619 & 56.2407 & 56.2407 & 56.2407 & 56.2407 & 0.0389 & 0.0013 & 0.0013 & 0.0013 & 0.0013 \\
\hline $2 / 12 / 2017$ & 56,180 & 56.2646 & 56.233 & 56.1908 & 56.1908 & 56.1908 & 0.1506 & 0.0943 & 0.0192 & 0.0192 & 0.0192 \\
\hline $3 / 12 / 2017$ & 56,100 & 56.1842 & 56.187 & 56.1168 & 56.1028 & 56.1028 & 0.1501 & 0.1551 & 0.0299 & 0.0049 & 0.0049 \\
\hline $4 / 12 / 2017$ & 56,035 & 56.0509 & 56.0509 & 56.0509 & 56.0509 & 56.0509 & 0.0284 & 0.0284 & 0.0284 & 0.0284 & 0.0284 \\
\hline $5 / 12 / 2017$ & 56,000 & 55.986 & 55.986 & 55.986 & 55.986 & 55.986 & 0.0251 & 0.0251 & 0.0251 & 0.0251 & 0.0251 \\
\hline $6 / 12 / 2017$ & 55,950 & 56.0042 & 55.951 & 55.951 & 55.951 & 55.951 & 0.0969 & 0.0018 & 0.0018 & 0.0018 & 0.0018 \\
\hline $7 / 12 / 2017$ & 55,950 & 55.922 & 55.922 & 55.943 & 55.943 & 55.943 & 0.05 & 0.05 & 0.0125 & 0.0125 & 0.0125 \\
\hline $8 / 12 / 2017$ & 55,900 & 55.999 & 55.901 & 55.901 & 55.901 & 55.901 & 0.177 & 0.0019 & 0.0019 & 0.0019 & 0.0019 \\
\hline $9 / 12 / 2017$ & 55,940 & 55.9042 & 55.9349 & 55.9349 & 55.9349 & 55.9349 & 0.064 & 0.009 & 0.009 & 0.009 & 0.009 \\
\hline $10 / 12 / 2017$ & 55,965 & 55.933 & 55.933 & 55.975 & 55.975 & 55.975 & 0.0572 & 0.0572 & 0.0178 & 0.0178 & 0.0178 \\
\hline $11 / 12 / 2017$ & 55,990 & 55.979 & 56 & 56 & 56 & 56 & 0.0197 & 0.0178 & 0.0178 & 0.0178 & 0.0178 \\
\hline $12 / 12 / 2017$ & 56,060 & 56.004 & 56.067 & 56.067 & 56.067 & 56.067 & 0.0999 & 0.0125 & 0.0125 & 0.0125 & 0.0125 \\
\hline $\begin{array}{c}13-12- \\
2017 \\
\end{array}$ & 56,170 & 56.1231 & 56.1791 & 56.1791 & 56.1791 & 56.1791 & 0.0836 & 0.0162 & 0.0162 & 0.0162 & 0.0162 \\
\hline $\begin{array}{c}14-12- \\
2017\end{array}$ & 56,280 & 56.2894 & 56.2894 & 56.2894 & 56.2894 & 56.2894 & 0.0166 & 0.0166 & 0.0166 & 0.0166 & 0.0166 \\
\hline $\begin{array}{c}15-12- \\
2017\end{array}$ & 56,295 & 56.3152 & 56.3152 & 56.3152 & 56.3152 & 56.3152 & 0.0358 & 0.0358 & 0.0358 & 0.0358 & 0.0358 \\
\hline $\begin{array}{c}16-12- \\
2017\end{array}$ & 56,300 & 56.3091 & 56.288 & 56.288 & 56.288 & 56.288 & 0.0161 & 0.0214 & 0.0214 & 0.0214 & 0.0214 \\
\hline $\begin{array}{c}17-12- \\
2017 \\
\end{array}$ & 56,300 & 56.3493 & 56.293 & 56.293 & 56.293 & 56.293 & 0.0875 & 0.0125 & 0.0125 & 0.0125 & 0.0125 \\
\hline $\begin{array}{c}18-12- \\
2017 \\
\end{array}$ & 56,330 & 56.3493 & 56.3352 & 56.3563 & 56.3352 & 56.3352 & 0.0342 & 0.0092 & 0.0467 & 0.0092 & 0.0092 \\
\hline $\begin{array}{c}19-12- \\
2017\end{array}$ & 56,390 & 56.3652 & 56.3652 & 56.4075 & 56.4075 & 56.4075 & 0.044 & 0.044 & 0.031 & 0.031 & 0.031 \\
\hline $\begin{array}{c}20-12- \\
2017\end{array}$ & 56,510 & 56.5098 & 56.5098 & 56.5098 & 56.5098 & 56.5098 & 0.0003 & 0.0003 & 0.0003 & 0.0003 & 0.0003 \\
\hline $\begin{array}{c}21-12- \\
2017 \\
\end{array}$ & 56,570 & 56.6089 & 56.5877 & 56.5877 & 56.5877 & 56.5877 & 0.0688 & 0.0313 & 0.0313 & 0.0313 & 0.0313 \\
\hline $\begin{array}{c}22-12- \\
2017 \\
\end{array}$ & 56,630 & 56.6336 & 56.6478 & 56.6478 & 56.6478 & 56.6478 & 0.0064 & 0.0314 & 0.0314 & 0.0314 & 0.0314 \\
\hline $\begin{array}{c}23-12- \\
2017\end{array}$ & 56,640 & 56.6937 & 56.6229 & 56.6229 & 56.6229 & 56.6229 & 0.0948 & 0.0302 & 0.0302 & 0.0302 & 0.0302 \\
\hline $\begin{array}{c}24-12- \\
2017\end{array}$ & 56,635 & 56.6896 & 56.6329 & 56.6329 & 56.6329 & 56.6329 & 0.0963 & 0.0037 & 0.0037 & 0.0037 & 0.0037 \\
\hline $\begin{array}{c}25-12- \\
2017 \\
\end{array}$ & 56,620 & 56.6279 & 56.6279 & 56.6279 & 56.6279 & 56.6279 & 0.014 & 0.014 & 0.014 & 0.014 & 0.014 \\
\hline $\begin{array}{c}26-12- \\
2017\end{array}$ & 56,620 & 56.6695 & 56.6129 & 56.6129 & 56.6129 & 56.6129 & 0.0875 & 0.0125 & 0.0125 & 0.0125 & 0.0125 \\
\hline $\begin{array}{c}27-12- \\
2017\end{array}$ & 56,640 & 56.6342 & 56.6342 & 56.6554 & 56.6554 & 56.6554 & 0.0103 & 0.0103 & 0.0272 & 0.0272 & 0.0272 \\
\hline $\begin{array}{c}28-12- \\
2017 \\
\end{array}$ & 56,630 & 56.6754 & 56.6329 & 56.6329 & 56.6329 & 56.6329 & 0.0802 & 0.0052 & 0.0052 & 0.0052 & 0.0052 \\
\hline $\begin{array}{c}29-12- \\
2017 \\
\end{array}$ & 56,620 & 56.6796 & 56.6229 & 56.6229 & 56.6229 & 56.6229 & 0.1052 & 0.0052 & 0.0052 & 0.0052 & 0.0052 \\
\hline $\begin{array}{c}30-12- \\
2017 \\
\end{array}$ & 56,600 & 56.5917 & 56.5917 & 56.6129 & 56.6129 & 56.6129 & 0.0147 & 0.0147 & 0.0228 & 0.0228 & 0.0228 \\
\hline $\begin{array}{c}31-12- \\
2017\end{array}$ & 56,560 & 56.5929 & 56.5505 & 56.5505 & 56.5505 & 56.5505 & 0.0582 & 0.0168 & 0.0168 & 0.0168 & 0.0168 \\
\hline & & & & & & MAPE & 0.06169 & 0.02535 & 0.018 & 0.01598 & 0.01598 \\
\hline
\end{tabular}


Pada penelitian ini dilakukan beberapa kali pengujian untuk memprediksi DMA tanggal 1- 31 Desember 2017 menggunakan rentang waktu data historis selama 3 bulan, 6 bulan, 9 bulan, dan 1 tahun, dengan nilai MAPE berdasar orde dan rentang waktu sebagai berikut:

TABEL XVI

HASIL MAPE BERDASARKAN ORDE DAN RENTANG WAKTU

\begin{tabular}{|l|c|c|c|c|c|c|}
\hline $\begin{array}{l}\text { Qrde } \\
\text { Bulan }\end{array}$ & 1 & 2 & 3 & 4 & 5 & Min \\
\hline 3 & 0.06169 & 0.02535 & 0.018 & 0.01598 & .01598 & $\mathbf{0 . 0 1 5 9 8}$ \\
\hline 6 & 0.15303 & 0.08363 & 0.0622 & 0.06643 & .05189 & $\mathbf{0 . 0 5 1 8 9}$ \\
\hline 9 & 0.20137 & 0.12475 & $\begin{array}{c}0.0666 \\
5\end{array}$ & 0.05508 & 0.0486 & $\mathbf{0 . 0 4 8 6}$ \\
\hline 12 & 0.20137 & 0.12043 & 0.079 & 0.0606 & 0.0486 & $\mathbf{0 . 0 4 8 6}$ \\
\hline Min & $\mathbf{0 . 0 6 1 6 9}$ & $\mathbf{0 . 0 2 5 3 5}$ & $\mathbf{0 . 0 1 8}$ & $\mathbf{0 . 0 1 5 9 8}$ & $\mathbf{. . 0 1 5 9 8}$ & \\
\hline
\end{tabular}

Berdasarkan hasil pengujian tersebut diketahui bahwa nilai MAPE terbaik untuk prediksi DMA untuk $1-31$ Desember 2017 adalah pada saat menggunakan rentang waktu 3 bulan dengan banyak orde adalah 5 .

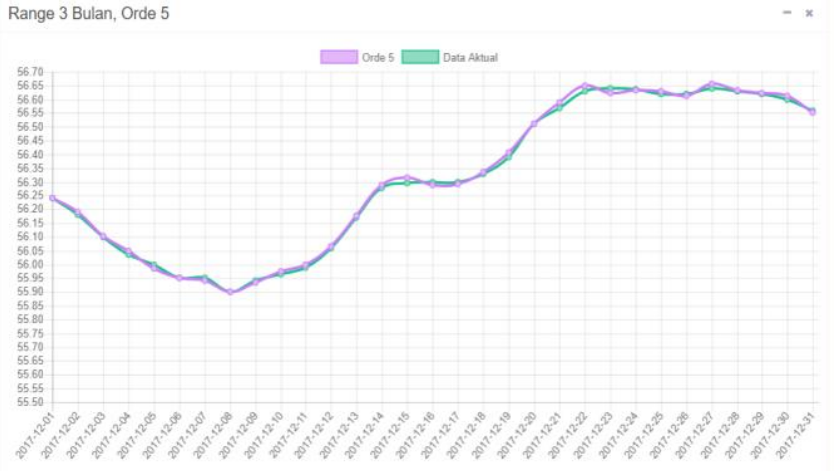

Gambar. 1 Grafik Hasil Prediksi Orde 5 untuk Rentang Waktu 3 Bulan

\section{KESIMPULAN}

Pada penelitian pediksi DMA dengan metode Multivariate High Order Fuzzy Time Series, didapatkan bahwa:

1. Faktor pendukung dan banyaknya orde dapat membantu meningkatkan keakuratan prediksi.

Faktor pendukung dan banyaknya orde berpengaruh ketika membentuk fuzzy logic relationship dan fuzzy logic relationship group, dimana keberadaan faktor pendukung dan banyaknya orde dapat memberikan lebih banyak variasi FLRG, yang dapat mengurangi keambiguitasan relasi antar fuzzy set, dan meningkatkan keakuratan hasil prediksi.

2. Hasil prediksi DMA dengan menggunakan metode Multivariate High Order fuzzy time series memiliki tingkat keakuratan yang tinggi, dimana nilai MAPE terbaik didapat pada saat pengujian dengan menggunakan rentang waktu tiga bulan dengan nilai MAPE untuk orde 1 hingga 5 secara berturut-turut adalah $0.06169 \%, 0.02535 \%, 0.018 \%, 0.01598 \%$, dan $0.01598 \%$.

\section{REFERENSI}

[1] Boaisha, Samira M, Forecasting Model Based on Fuzzy time series Approach. The 11th International Arab Conference on Information Technology (ACIT'2010), 2010.

[2] Chen, Shyi Ming, Forecasting Enrollments Based On High-order Fuzzy time series. Cybernatics and Systmes: An International Journal, 2008, vol. 33, no. 1.

[3] Hanke, John E. dan Dean Winchern, Business Forecasting. Pearson Education Limited: Edinburg Gate, 2005.

[4] Hansun, Seng, Peramalan Data IHSG Menggunakan Fuzzy time series. Jurnal IJCSS, 2012, vol. 6, no. 2.

[5] Jilani, Tahseen A, S. M. Aqil Burney, dan C Ardil, Multivariate High Order Fuzzy Time Series Forecasting for Car Road Accidents. International Journal of Computational Intelligence, 2008, vol. 4, no.1.

[6] __ Multivariate Stockhasting Fuzzy Forecasting Models" Expert System With Application, 2008, vol 35.

[7] Lee, Li-Wei, dkk, Handling Forecasting Problems Based on TwoFactors High-Order Fuzzy Time Series, IEEE Transactions of Fuzzy Systems, 2006, vol 14, no. 3.

[8] Porter, John E. Porter dan Meredith Stevenson, Fuzzy time series Forecasting Using Percentage Change as The Universe Discourse, World Academy of Science, Engineering and Technology, 2009, vol. 55.

[9] Satria, I Made Candra, I Komang Gde Sukarsa, dan Ketut Jayanegara, Peramalann Jumlah Wisatawan Australia yang Berkunjung ke Bali Menggunakan Multivariat Fuzzy Time Series, E-Jurnal Matematika, 2015, vol 4, no. 3.

[10] Song, Qiang dan B.S. Chissom, Forecasting Enrollments with Fuzzy Time Series - Part I, Fuzzy sets and Systems, 1996, vol. 54.

[11] Supranto, J, Statistik Teori dan Aplikasi, Edisi Keenam. Erlangga: Jakarta, 2000.

[12] Swanson, David. A, MAPE-R: A Resscaled Measure of Accuracy for Cross-Sectional Forecast, Univeristy of California, 2011.

[13] Tim Penyusun, Feasibility Study Pembangkit Listrik Tenaga Mikro Hidro (PLTMH), CV. Mitra Suplindo Pertanian: Bogor, 2010

[14] Winasis, Optimasi Operasi Pembangkit Listrik Tenaga Air (PLTA) Meggunakan Linear Programming dengan Batasan Ketersediaan Air. Jurnal Dinamika Rekayasa. 2013, vol. 9, no. 2. 